\title{
CAZADORES RECOLECTORES EN TIEMPOS FORMATIVOS. TRAYECTORIA HISTÓRICA LOCAL EN LA PRECORDILLERA DEL EXTREMO NORTE DE CHILE ${ }^{1}$
}

\author{
HUNTER GATHERERS DURING FORMATIVE TIMES. LOCAL HISTORICAL \\ TRAJECTORY IN THE FOOTHILLS OF THE FAR NORTH CHILE
}

\author{
Marcela Sepúlveda ${ }^{2}$ Luis Cornejo ${ }^{3}$, Daniela Osorio ${ }^{4}$, Mauricio Uribe $^{5}$, Carolina Llanos 6 \\ Camila Castillo $^{7}$
}

\begin{abstract}
Un conjunto de dataciones, síntesis de excavaciones y análisis de materiales asociados de la cuenca alta del valle de Azapa, en torno al río Tignamar ( $2.800-3.800 \mathrm{msm}$ ) nos permiten discutir la ocurrencia de procesos socio-culturales, entre cal. 1.500 a.C.-650 d.C., en la precordillera del extremo norte de Chile. Definido, en general, a partir de referencias provenientes de otros núcleos de desarrollo como los Valles costeros o el Altiplano, el Formativo local es evaluado y discutido a la luz de los datos de tres localidades arqueológicas: Pampa El Muerto, Pampa Oxaya y Mullipungo. Se propone la continuidad de grupos móviles con un modo de vida basado en la caza-recolección, quienes habrían progresivamente incorporado la cerámica y gestión de recursos animales, evidenciado por el arte rupestre. Se afirma, en consecuencia, la existencia de una trayectoria histórica local particular durante tiempos Formativo en la Precordillera de Arica, de los Andes Centro Sur.
\end{abstract}

Palabras claves: cazadores-recolectores, Norte de Chile, Formativo, lítica, cerámica, camélidos.

A set of dates, from a summary of excavations and of analyses of associated material from the upper basin of the Azapa valley, around the Tignamar River (2,800 and 3,800 masl), allows us to discuss the occurrence of socio-cultural processes, between cal. 1,500 BC-650 AD, in the Precordillera (foothills) of the far north of Chile. Defined in general based on references from other developmental nuclei, such as the coastal valleys or the high plateau, the local Formative is evaluated and discussed in light of the data obtained from three archaeological locations: Pampa El Muerto, Pampa Oxaya and Mullipungo. We suggest the continuity of mobile groups with a hunting-gathering way of life, who would have progressively incorporated ceramics and the management of animal resources, as evidenced by rock art. Consequently, the existence of a particular local historical trajectory during the Formative times is proposed for the Precordillera of Arica, in the South-Central Andes.

Key words: Hunter-gatherers, Northern Chile, Formative, lithic, ceramic, camelids.

Aunque la excesiva tiranía tipológica imperante en la arqueología andina en torno a categorizaciones como Formativo y su relación con la agricultura, la aparición de la cerámica y el sedentarismo genera siempre cierto debate (Cornejo y Sanhueza 2003; Dillehay 2014; Lumbreras 2006; Núñez 1989; Uribe y Adán 2012), coincidimos con Gnecco y Lagenbaek (2006) que estas son "inevitables" y necesarias. No es posible negar que estos conceptos, al igual que secuencias cronológicas establecidas como períodos, horizontes y fases basados en rasgos diagnósticos distribuidos en el espacio durante determinados lapsos de tiempo (Willey y Phillips 1958), sustentan ordenamientos necesarios para la arqueología regional. universales u homogéneas, ocultando así procesos o trayectorias históricas locales variables y/o arrítmicos (Gnecco y Lagenbaek 2006).

En los Andes Centro Sur, el paso de un modo de vida cazador-recolector móvil a otro productor de alimentos sedentario ha sido comúnmente considerado

\footnotetext{
Una primera versión de este artículo fue presentada en el XIX Congreso Nacional de Arqueología Argentina, Tucumán (agosto 2016), en el marco del simposio "El tránsito de modos de vida cazadores-recolectores a agro-pastoriles en la porción meridional de los Andes Centro-Sur: Trayectorias de continuidad y cambio". Este manuscrito fue evaluado por pares externos y editado por el comité Editorial de Chungara y los editores invitados Salomón Hocsman y Francisco Gallardo.

2 Instituto de Alta Investigación, Universidad de Tarapacá. Arica, Chile. marcelaasre@ gmail.com / msepulveda@uta.cl Departamento de Antropología, Universidad Alberto Hurtado. Santiago, Chile.1cornejo@outlook.com

4 Program PhD, Institute of Archaeology, University College London, Inglaterra. Daniosorio8@gmail.com; daniela.osorio.15@ucl.ac.uk 5 Departamento de Antropología, Universidad de Chile. Santiago, Chile. muribe@uchile.cl

6 Dirección postal Tucapel 2103, Arica, Chile. carolinallanosb@gmail.com

7 Programa de Doctorado en Antropología Universidad de Tarapacá - Universidad Católica del Norte. Arica, Chile. camilapaz.f@hotmail.com
}

Recibido: febrero 2017. Aceptado: enero 2018.

http://dx.doi.org/10.4067/S0717-73562018005000301. Publicado en línea: 23-febrero-2018. 
un hito diagnóstico para distinguir los periodos Arcaico (8.000-1.500 a.C.) y Formativo (1.500 a.C.500 d.C.). Se propone que tras cambios climáticos coincidentes con el Arcaico Medio (6.000-4.000 a.C.) conducentes a condiciones ambientales más similares a las actuales, se modifica el patrón de asentamiento, se instauran nuevas estrategias de subsistencia y formas productivas (agricultura y/o pastoralismo), junto con un importante crecimiento demográfico, nuevas formas de organización social y consecuentemente nuevas prácticas simbólicas e ideológicas, así como innovaciones y desarrollos tecnológicos -construcciones arquitectónicas monumentales, el manejo del agua, la cerámica, metalurgia o textilería- (Aldenderfer 2001, 2002, 2010; Craig et al. 2010; Craig 2011 y 2012; Dillehay 2014; Flores Blanco 2014; Muñoz 2004; Núñez, Cartajena, Carrasco y de Souza 2006; Núñez, Cartajena, Carrasco, de Souza et al. 2006; Núñez y Santoro 2011; Marquet et al. 2012; Yacobaccio 2012) -procesos no exento de niveles de violencia intergrupal, como en el caso Chinchorro (Standen et al. 2014). Adicionalmente, se incrementan los intercambios de recursos excedentarios, alimenticios u ornamentales, cuya producción o uso parece controlado por grupos de poder o líderes, evidencia de una organización social con mayor diferenciación y jerarquización (Aldenderfer 2004, 2010; Castillo y Sepúlveda 2015, 2017; Craig 2005; Gallardo y de Souza 2008; Yacobaccio 2012).

El lapso específico entre el Arcaico y el Formativo ( 2.500-1.500 a.C.) ha sido regularmente definido como "período de transición" o Arcaico Terminal (Aldenderfer 2002; Craig 2005, 2011), al evidenciar con mayor claridad los procesos de cambios sociales, económicos, políticos e ideológicos antes indicados. Hacer referencias a sociedades en tránsito, entre un modo de vida cazador recolector a otro productor de alimentos, supondría poder identificar en el registro arqueológico indicadores vinculados estrictamente a la subsistencia, dando así cuenta de procesos de cambio entre estados dicotómicos. Sin embargo, que estas transformaciones en el ámbito económico hayan ocurrido, no necesariamente involucraron modificaciones en todas las esferas -sociales, políticas, ideológicas- de estas sociedades (Cornejo y Sanhueza 2003; Dillehay 2014; Lumbreras 2006; Núñez 1989). $\mathrm{Y}$ si bien se vincularon, estas pudieron ocurrir a ritmos distintos y no siempre implicar toda una comunidad $\mathrm{o}$ al conjunto de individuos que la conformaron. El problema mayor sigue siendo, entonces, la posibilidad concreta de visualizar dichos cambios, pues muchos debieron iniciarse antes de ser perceptibles en el registro arqueológico (Lavallée 2006), en contextos de cazadores recolectores "complejos" (Hocsman 2002; Politis 1996; Yacobaccio 2006). Hoy existen suficientes argumentos como para abordar los procesos "de transición" entre el Arcaico y el Formativo, sus ocurrencias, ritmos y trayectorias históricas, así como sus variadas formas de expresión.

En el norte de Chile, variadas investigaciones han justamente discutido las consecuencias de la adopción de la agricultura durante el Formativo, al no afectar a todos similarmente, con diferencias inclusive individuales y, por ende, intra-grupos (Diaz-Zorita et al. 2016; García et al. 2014; Santana et al. 2015; Silva-Pinto et al. 2014). Al interior de Antofagasta, la caza sigue siendo significativa en sociedades formativas, paralelamente al manejo de rebaños de camélidos domésticos (Gallardo y de Souza 2008; Núñez 1989); mientras que en la costa grupos mantienen un modo de vida cazador recolector marinos, pese a establecer estrechos vínculos con grupos agropastoriles del interior hasta tiempos históricos (Ballester y Gallardo 2011; Bittman 1986; Gallardo et al. 2017; Llagostera 1979). Características tan claramente definidas hasta hace algunas décadas, encuentran actualmente distintas formas de expresión y conllevan a la necesaria discusión de paradigmas evolutivos fervientemente enunciados aún en la literatura de los Andes Centro Sur.

En la precordillera de Arica, el lapso entre 1.500 a.C. y 650 d.C., coincidente con el Formativo Circumtiticaca (Hastorf 2008), aunque acotado a 1.000 a.C. y 500 d.C. en los Valles Occidentales del norte de Chile (Muñoz et al. 2016), poseía hasta ahora escasos antecedentes. Sin embargo, investigaciones sistemáticas desde hace 10 años nos permiten junto a datos previamente publicados intentar cierta sistematización y caracterización. Entre ellos, se menciona la presencia de cerámica con desgrasante vegetal en Hakenasa y Piñuta, en la cuenca alta del valle de Lluta aludiendo a semejanzas con tipos de la costa (Santoro 1989). Junto a la presencia de algunos tubérculos y una nueva modalidad de asentamiento a partir del Arcaico Tardío (6.000-3.500 a.C.), Santoro y Chacama (1984:83) plantean la ocurrencia de cambios significativos en las sociedades cazadoras, con fuertes bases pecuarias. Inclusive, la popularización de dos tipos de instrumentos (puntas escotadas y cuchillos triangulares) es planteada como prueba de un nuevo estadio (Santoro 1989:55). Schiappacasse y Niemeyer (1996:274) interpretan la ocupación del alero de Itiza, contemporánea a Piñuta, como parte de un "sistema de asentamiento de comunidades aldeanas agropastoriles que complementaron sus recursos con actividades de caza". Finalmente, para el sector de Pampa El Muerto (PM-3 y PM-8), se propone cierta continuidad en el tipo de ocupaciones de los aleros desde el Arcaico Tardío y durante el Formativo, por parte de grupos cazadores recolectores móviles (Sepúlveda et al. 2013). 
En este trabajo presentamos una síntesis y discusión de variados contextos inéditos, definidos tras prospecciones, excavaciones y dataciones sistemáticas (Figura 1; Sepúlveda et al. 2018) en tres localidades de la precordillera, donde hasta ahora el lapso correspondiente al Formativo (1.500 a.C. y 650 d.C.) contaba con escasas evidencias. Para ello, recopilamos un total de 63 dataciones y sintetizamos los resultados del análisis lítico, cerámico y zooarqueológico de estratos fechados, tanto del Arcaico Tardío como del Formativo, de modo de contrastar sus características. A partir de esto, discutimos la vigencia en tiempos Formativos de ocupaciones relacionadas con grupos móviles que mantendrían un modo de vida basado en la caza recolección, pese a introducirse el pastoreo y consumo de recursos vegetales domesticados. Si bien escasa, la cerámica de características formativas identificada permite dar cuenta que estos grupos altoandinos accedieron también a esta tecnología mediante contactos con grupos de regiones vecinas. La ausencia de cambios evidentes y abruptos en el registro arqueológico para distinguir grupos cazadores recolectores móviles arcaicos de otros sedentarios agropastoriles formativos dificultó, sin duda, hasta ahora la visibilización de quienes habrían optado por su propia trayectoria histórica.

\section{Lapso Arcaico Tardío-Formativo en la Precordillera de Arica}

El conjunto de 63 dataciones -48 publicadas (Gayó et al. 2015; Osorio et al. 2016; Sepúlveda et al. 2017; Tabla 1), y 15 inéditas fueron calibradas con el programa Calib 7.0 y la curva de calibración ShCal13. Se graficaron individualmente y ordenaron de manera secuencial los rangos de cada fecha con una probabilidad de 95\% y (Figura 2), para luego representar la acumulación de probabilidades del conjunto en rangos de 500 años y así evaluar variaciones en el tiempo (Figura 3 ).

El total de fechas no calibradas recopiladas se ubican entre 5.910 \pm 90 (BETA- 40958) y $1.530 \pm 30$ años a.p. (BETA-335685), obtenidas en los sitios de Patapatane y Pampa El Muerto 15, respectivamente (Osorio et al. 2016; Standen y Santoro 1994). Estas equivalen a casi la mitad de todas las dataciones existentes para las tierras altas del extremo norte de Chile. En su mayoría se trata de dataciones de las cuencas altas del valle de Lluta (46,03\%) y de Azapa $(53,97 \%)$, obtenidas en los últimos 10 años (48 de $63,76,19 \%)^{1}$. En Lluta seis sitios presentan 29 fechas en el rango de cal. 4.953 a.C. a 642 d.C.; frente a 17 sitios con 34 fechados en Azapa en torno a la cuenca del río de Tignamar (Tabla 1). En la mayoría se trata de abrigos rocosos con pinturas rupestres, salvo cuatro casos recientes de sitios a cielo abierto (Tabla 2).
En general, se observa una ocupación continua entre 5.000 años a.C. y 650 d.C., es decir, desde momentos coincidentes con el Arcaico Medio (PAT, PM-8 y HAK) hasta el Formativo Tardío, abarcando todas las tierras altas -valles de Lluta y Azapa(Figura 2). Si bien otros sitios pudieron también ser ocupados y no ser datados por problemas de muestreo o disponibilidad de material para fechar, su ocupación parece haberse iniciado en el Arcaico Tardío o Formativo, por ejemplo, CNFL, MU-4, $\mathrm{CEP}^{2}$. De estos, 36 fueron ocupados entre cal. 4.000 y 1.500 a.C.; mientras 24 entre cal. 1.500 a.C. y 650 d.C., lo cual constituye un sustento para discutir un lapso hasta hoy invisibilizado en la secuencia cronológica de las tierras altas de la región. En el gráfico de acumulación de probabilidades (Figura 3 ) se observa una distribución de frecuencia bimodal con dos puntos máximos: un primer momento en torno a cal. 2.500 años a.C., y un segundo hacia cal. 500 a.C. Se reconoce un punto de inflexión hacia cal. 1000 a.C., lo que puede ser interpretado por un uso menos recurrente de este espacio altoandino y, por tanto, como un cambio en el patrón de movilidad, aunque también por un problema de muestreo.

\section{Tecnología Lítica y Funcionalidad de Sitios}

El análisis del material lítico abordó la identificación de las fases de las secuencias de producción (Andrefsky 2005) y las actividades realizadas al interior de los aleros para evaluar su funcionalidad (Binford 1980; Nelson 1991). Los instrumentos tallados se analizaron según la clasificación morfológica y funcional de Aschero (1975 y 1983).

Pensamos las ocupaciones aquí analizadas en relación a un sistema de ocupación de la Puna con antecedentes en el Arcaico Temprano (Osorio, Capriles et al. 2017; Osorio, Steele et al. 2017), cuando la movilidad se habría desarrollado de forma principalmente latitudinal y no sólo longitudinal. Las características tecnológicas apuntan al desarrollo de una tradición andina y una unidad cultural de este espacio, definidas a partir de similitudes en las tecnologías líticas y las tipologías de puntas de proyectil desde el Temprano, reafirmado en su fase Tardía por la construcción de un paisaje común evidenciado por el arte rupestre (Sepúlveda et al. 2013, 2017).

Si observamos las dos localidades que presentan mayor cantidad de yacimientos arqueológicos estudiados -Pampa El Muerto y Mullipungo (Figuras 1 y 4)-, es posible precisar variadas diferencias tanto a nivel de conjunto como entre los sitios estudiados. En la primera, los aleros PM-8, 11 y 12 son pequeños con dataciones en el Arcaico Tardío, a diferencia de los aleros PM-3 y 15 de mucho mayor tamaño (Tabla 


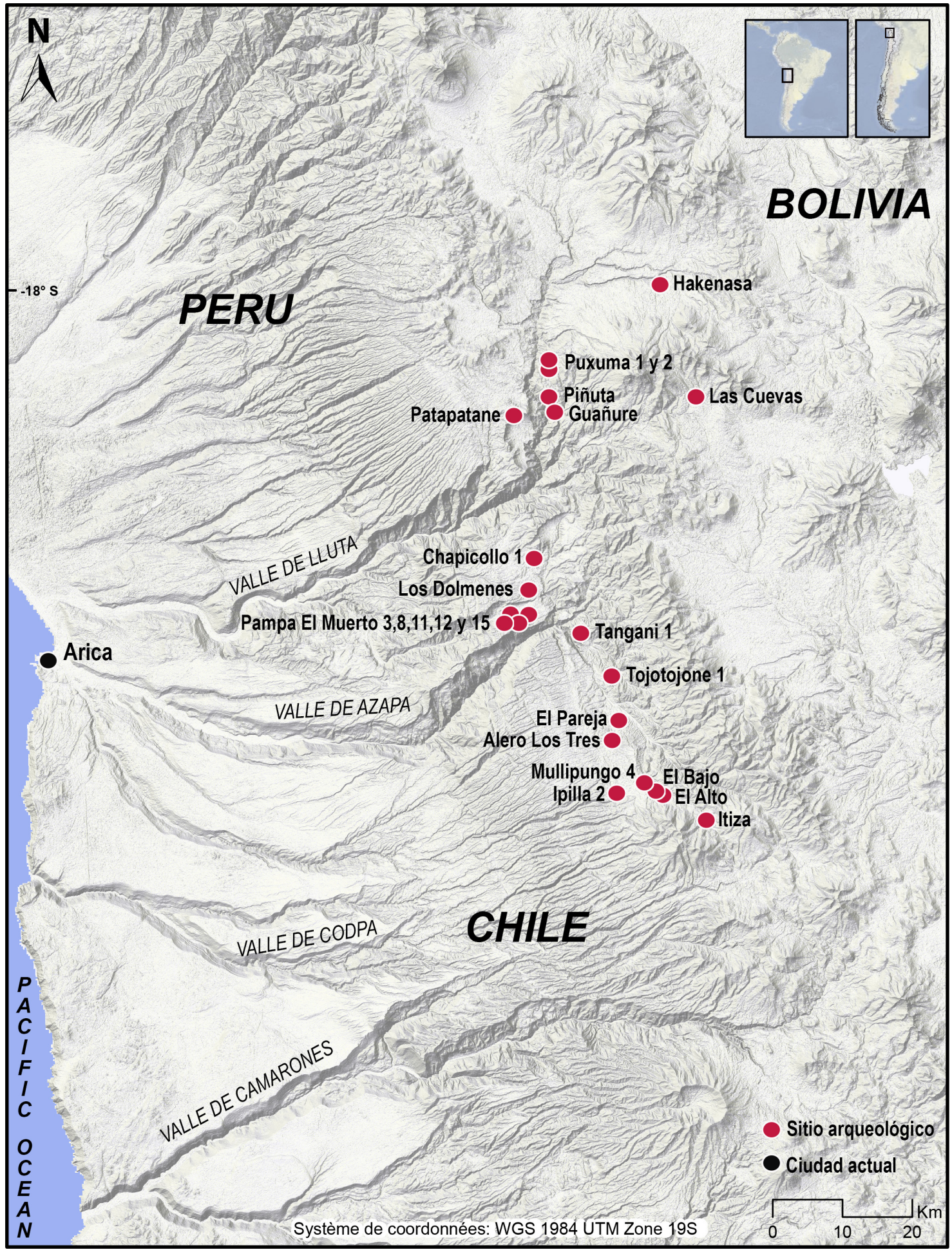

Figura 1. Mapa de localización de sitios arqueológicos. Location map of archaeological sites. 
Tabla 1. Síntesis de sitios Arcaico Tardío-Formativo en la precordillera de Arica. Synthesis of Late Archaic and Formative sites from the foothills of Arica.

\begin{tabular}{|c|c|c|c|c|c|c|c|c|c|c|}
\hline & & & & & & & & $\begin{array}{l}\text { Asi } \\
\text { cron }\end{array}$ & $\begin{array}{l}\text { nación } \\
\text { lógica }^{1}\end{array}$ & Referencias \\
\hline Valle & $\begin{array}{l}\text { Localidad } \\
\text { Arqueológica }\end{array}$ & $\begin{array}{l}\text { Cantidad } \\
\text { de sitios }\end{array}$ & $\begin{array}{l}\text { Cantidad de } \\
\text { dataciones }\end{array}$ & Sitio & Sigla & $\begin{array}{l}\text { Tipo de } \\
\text { sitio }\end{array}$ & Altitud & $\begin{array}{l}\text { Arcaico } \\
\text { Tardío }\end{array}$ & Formativo & \\
\hline \multirow{6}{*}{ 总 } & \multirow{6}{*}{ Alto Lluta } & \multirow{6}{*}{6} & \multirow{6}{*}{29} & Hakenasa & HAK & Alero & 4.100 & $\mathrm{X}$ & $\mathrm{X}$ & $\begin{array}{c}\text { Santoro y Núñez } \\
1987\end{array}$ \\
\hline & & & & Puxuma-1 & PUX-1 & Alero & 3.600 & $\mathrm{X}$ & & $\begin{array}{l}\text { Santoro y Chacama } \\
\text { 1982, Osorio et al. } 2016\end{array}$ \\
\hline & & & & Puxuma-2 & PUX-2 & Alero & 3.600 & $\mathrm{X}$ & $\mathrm{X}$ & $\begin{array}{c}\text { Santoro y Chacama } \\
\text { 1982, Osorio et al. } 2016\end{array}$ \\
\hline & & & & Piñuta & PIÑ & Alero & 3.600 & $\mathrm{X}$ & $\mathrm{X}$ & $\begin{array}{l}\text { Santoro y Chacama } \\
\text { 1982, Osorio et al. } 2016\end{array}$ \\
\hline & & & & Guañure & GUA & Alero & 3.600 & $\mathrm{X}$ & & $\begin{array}{c}\text { Santoro y Chacama } \\
1982\end{array}$ \\
\hline & & & & Patapatane & PAT & Alero & 3.800 & $\mathrm{X}$ & $\mathrm{X}$ & $\begin{array}{c}\text { Santoro y Chacama } \\
\text { 1984, Santoro et al. } 2001\end{array}$ \\
\hline \multirow{17}{*}{ 芯 } & Zapahuira & 1 & 3 & $\begin{array}{l}\text { Los } \\
\text { Dólmenes }\end{array}$ & DOL & Alero & 3.100 & $\mathrm{X}$ & $\mathrm{X}$ & $\begin{array}{c}\text { Santoro, } \\
\text { comunicación personal, } 2015 \\
\text { Sepúlveda et al 2013, } \\
\text { Osorio et al. } 2016\end{array}$ \\
\hline & \multirow{6}{*}{$\begin{array}{l}\text { Pampa } \\
\text { El Muerto }\end{array}$} & \multirow{6}{*}{6} & \multirow{6}{*}{9} & $\begin{array}{l}\text { Pampa } \\
\text { El Muerto } \\
\quad(-2 ?)\end{array}$ & PM-2 & Alero & 3.301 & & $\mathrm{X}$ & Sepúlveda et al. 2013 \\
\hline & & & & $\begin{array}{c}\text { Pampa } \\
\text { El Muerto } \\
-3\end{array}$ & PM-3 & Alero & 3.269 & & $\mathrm{X}$ & Sepúlveda et al. 2013 \\
\hline & & & & $\begin{array}{c}\text { Pampa } \\
\text { El Muerto } \\
-8\end{array}$ & PM-8 & Alero & 3.260 & $\mathrm{X}$ & $\mathrm{X}$ & Sepúlveda et al. 2013 \\
\hline & & & & $\begin{array}{l}\text { Pampa } \\
\text { El Muerto } \\
-11\end{array}$ & PM-11 & Alero & 3.270 & $\mathrm{X}$ & & FONDECYT 1130808 \\
\hline & & & & $\begin{array}{l}\text { Pampa } \\
\text { El Muerto } \\
-12\end{array}$ & PM-12 & Alero & 3.195 & $\mathrm{X}$ & & FONDECYT 1130808 \\
\hline & & & & $\begin{array}{l}\text { Pampa } \\
\text { El Muerto } \\
-15\end{array}$ & PM-15 & Alero & 3.174 & & $\mathrm{X}$ & $\begin{array}{c}\text { Santoro, } \\
\text { comunicación personal, } 2015 \\
\text { Osorio et al. } 2016\end{array}$ \\
\hline & Tangani & 1 & 3 & Tangani 1 & TAN-1 & Alero & 3.100 & $\mathrm{X}$ & & Sepúlveda et al. 2013 \\
\hline & Belen & 1 & 4 & Tojotojone 1 & TO-1 & Alero & 3.600 & $\mathrm{X}$ & $\mathrm{X}$ & $\begin{array}{l}\text { Santoro et al. 2011, } \\
\text { Osorio et al. 2016, } \\
\text { FONDECYT } 1130808\end{array}$ \\
\hline & \multirow{2}{*}{$\begin{array}{l}\text { Pampa } \\
\text { Oxaya }\end{array}$} & \multirow{2}{*}{2} & \multirow{2}{*}{3} & $\begin{array}{c}\text { Cueva } \\
\text { El Pareja }\end{array}$ & CEP & Alero & 3.147 & $\mathrm{X}$ & & FONDECYT 1130808 \\
\hline & & & & $\begin{array}{c}\text { Alero } \\
\text { Los Tres }\end{array}$ & ATR & Alero & 3.003 & $\mathrm{X}$ & & FONDECYT 1130808 \\
\hline & \multirow{4}{*}{ Mullipungo } & \multirow{4}{*}{4} & \multirow{4}{*}{10} & Mullipungo 4 & MU-4 & Alero & 3.551 & & $\mathrm{X}$ & FONDECYT 1130808 \\
\hline & & & & Confluencia & CNFL & $\begin{array}{l}\text { Cielo } \\
\text { abierto }\end{array}$ & & & $\mathrm{X}$ & FONDECYT 1130808 \\
\hline & & & & $\begin{array}{c}\text { Alero } \\
\text { El Bajo }\end{array}$ & AEB & Alero & 3.600 & $\mathrm{X}$ & & FONDECYT 1130808 \\
\hline & & & & El Alto & EAL & $\begin{array}{l}\text { Cielo } \\
\text { abierto }\end{array}$ & 3.562 & $\mathrm{X}$ & & FONDECYT 1130808 \\
\hline & Ipilla & 1 & 1 & Ipilla 2 & IPI-2 & $\begin{array}{l}\text { Cielo } \\
\text { abierto }\end{array}$ & 3.400 & & $\mathrm{X}$ & Santoro et al. 2011 \\
\hline & Itiza & 1 & 1 & Itiza & ITI & Alero & 3.860 & & $\mathrm{X}$ & $\begin{array}{c}\text { Schiappacasse y Niemeyer } \\
1996\end{array}$ \\
\hline & Totales & 23 & 63 & & & & & & & \\
\hline
\end{tabular}




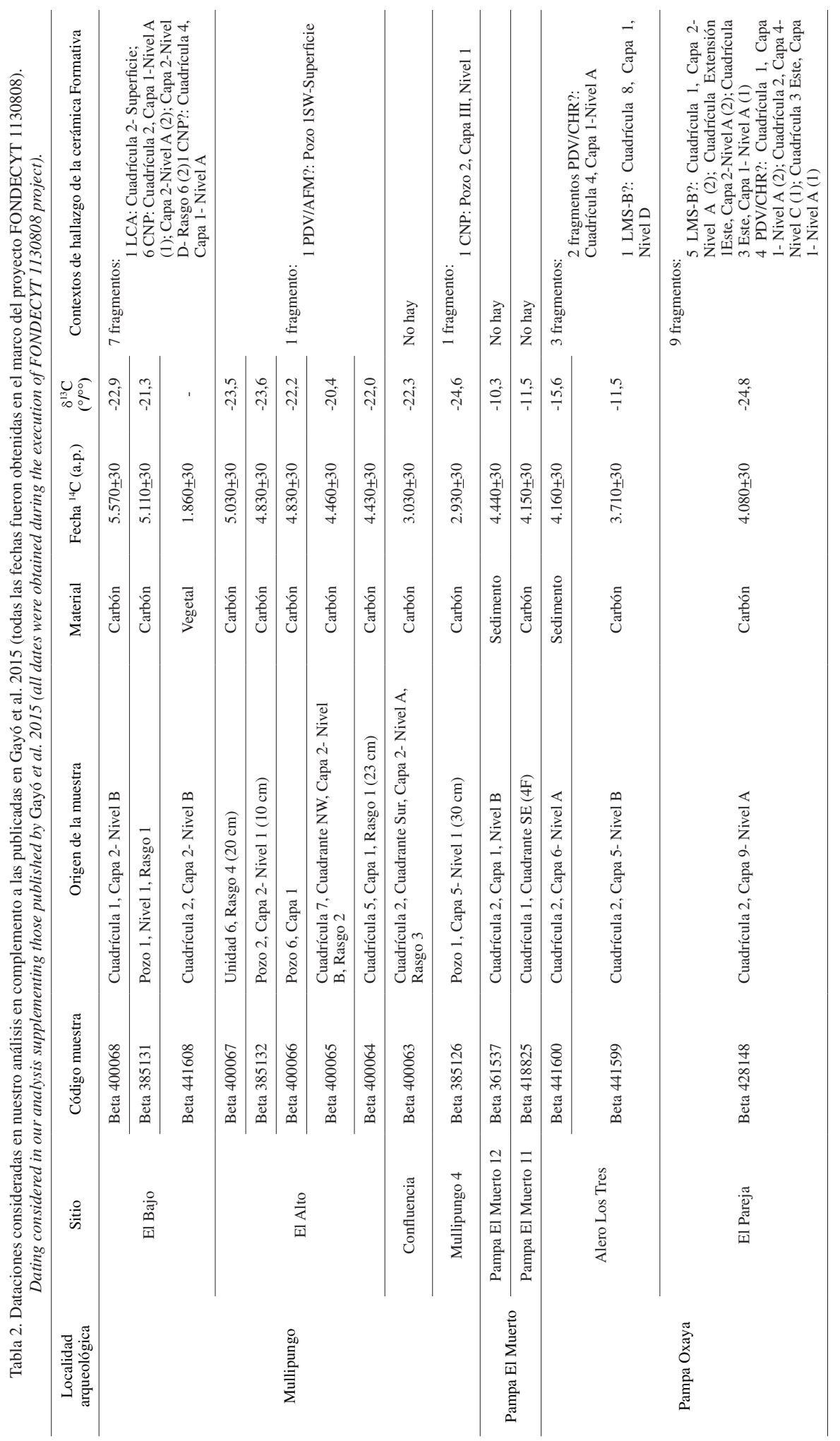



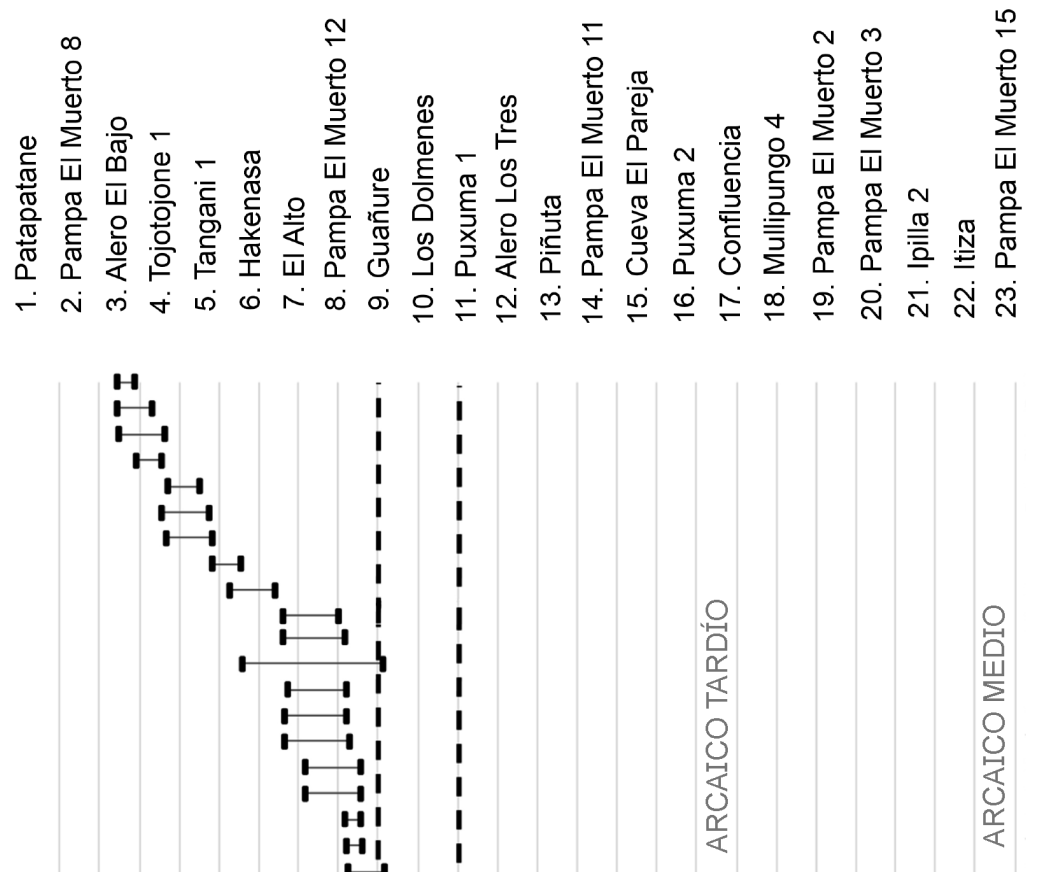

ח

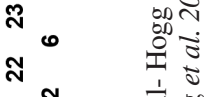

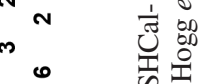

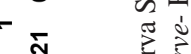

กิ

$\stackrel{2}{\circ}$ กี

-

$+\infty$

$\stackrel{0}{\pi} \pi \dot{0}$

$+\circ$

- क t

o

๓

$\div \div \quad$ Ud

- $\quad$ ๙ँ:

$\div$ ช

m

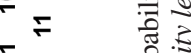

$\div$ ๓

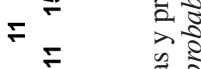

$+\quad$.

$\div \div \frac{0}{2}$

○

당

- 을

${ }^{\circ} 0$ क्ष

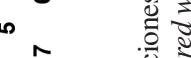

$\infty$

ก

-

- $n$

m

เ

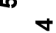

N 


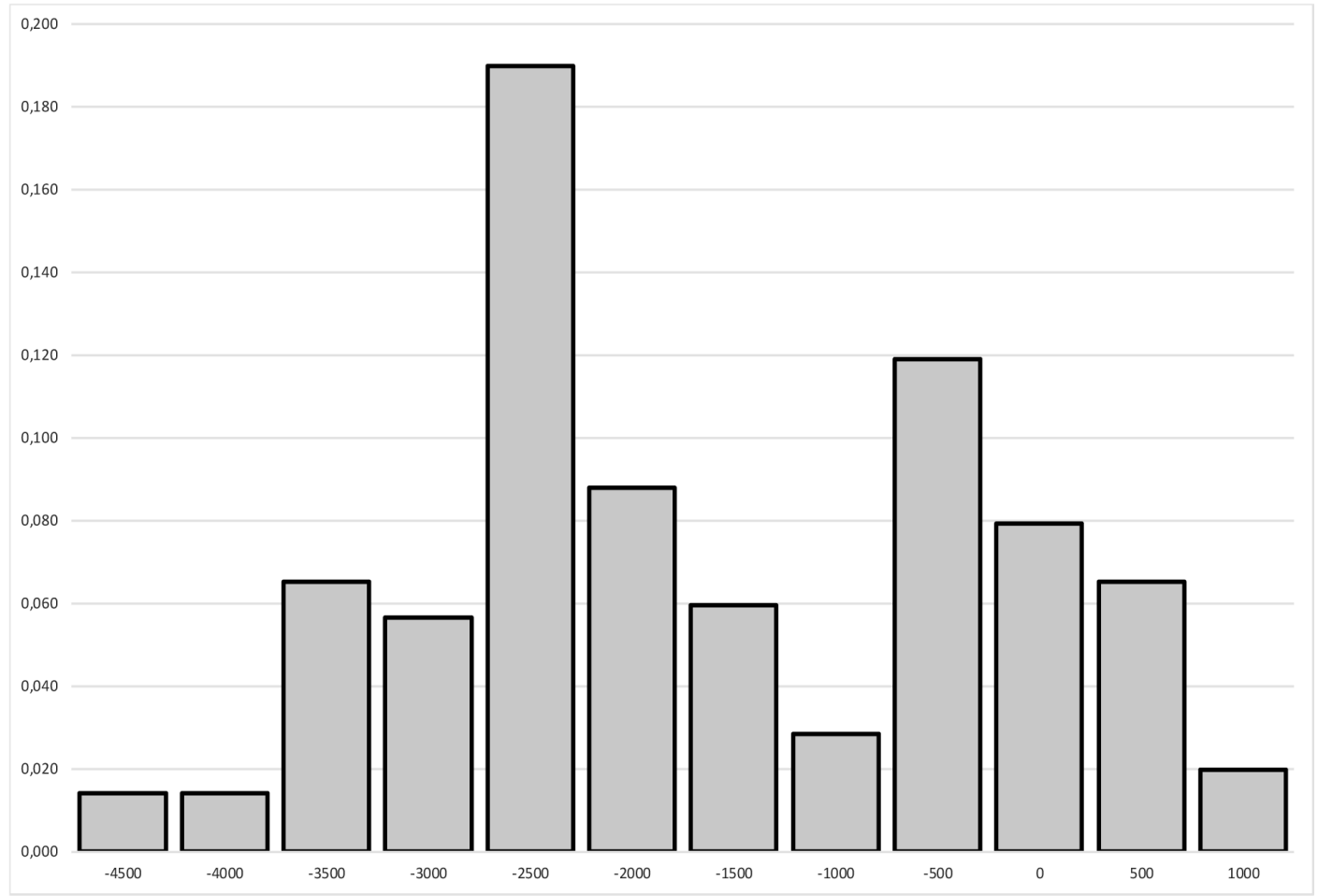

Figura 3. Acumulación de probabilidades en rango de 500 años. Cumulative probability by 500 years.

2). PM-3, con dataciones en el Formativo, presenta una mayor variabilidad de artefactos formatizados (Tabla 3), entre los que predominan los de uso cortante, para el faenamiento y preparación de alimentos, asociados a un conjunto de variados pequeños eventos de quema (Figura 4). La presencia de una mano de moler, además de preformas, puntas de proyectil, una muesca, un núcleo bipolar y un raspador, junto con la mayor cantidad de material lítico, casi exclusivamente de materias primas silíceas $(92,86 \%)$ seguidas de andesitas, basaltos y riolitas en menor frecuencia (Tabla 3; Osorio et al. 2016; Sepúlveda et al. 2013) inciden en mostrar una amplia variedad de actividades desarrolladas en el sitio, con una marcada presencia de talla bifacial distinguida en los derivados. Estas características, entre las que además se incluye la presencia de mineral de cobre, lo distinguen de los demás aleros, cuyas ocupaciones son mucho más acotadas y se insertan mayoritariamente en el Arcaico Tardío (Tabla 4; Sepúlveda et al. 2013). PM-15 con fechas tempranas del Formativo cuenta con muy pocos derivados $(\mathrm{N}=44)$ de tamaños pequeños, sin corteza y mayoritariamente desechos de retoque en materias primas exclusivamente silíceas, vinculados a fases tardías de manufactura de instrumentos. Destacan, sin embargo, una punta de proyectil de tipo triangular de base recta y otro fragmento de pedúnculo de punta, semillas no identificadas, un zuro de maíz y huesos de fauna menor, lo que se interpreta como un cambio importante en las actividades desarrolladas, en comparación con los niveles anteriores también arcaicos, incorporando prácticas vinculadas con cultígenos (Tabla 3; Osorio et al. 2016).

Los cuatro sitios de Mullipungo también presentan variadas situaciones (Tabla 3 ). Si bien de compleja estratigrafía, la ocupación del Arcaico Tardío del Alero El Bajo muestra principalmente fases finales de la cadena operativa con materias primas de alta calidad, esencialmente silíceas (79\%), además de andesita basáltica $(9,9 \%)$ y toba $(7,2 \%)$. Los instrumentos, de corte expeditivo, corresponden a raederas y una gubia, posible de vincular con trabajo en materiales blandos como madera (Tabla 3; Almonacid 2016). Entre todos los sitios excavados, destaca el sitio El Alto por su tamaño con una importante densidad de materiales en estratigrafía y en superficie. Análisis preliminares dan cuenta de un campamento temporal de actividades múltiples con predominancia de fases finales de reducción y formatización de instrumentos (Llanos 2014). Los sílices, jaspes y basaltos se presentan abundantes 


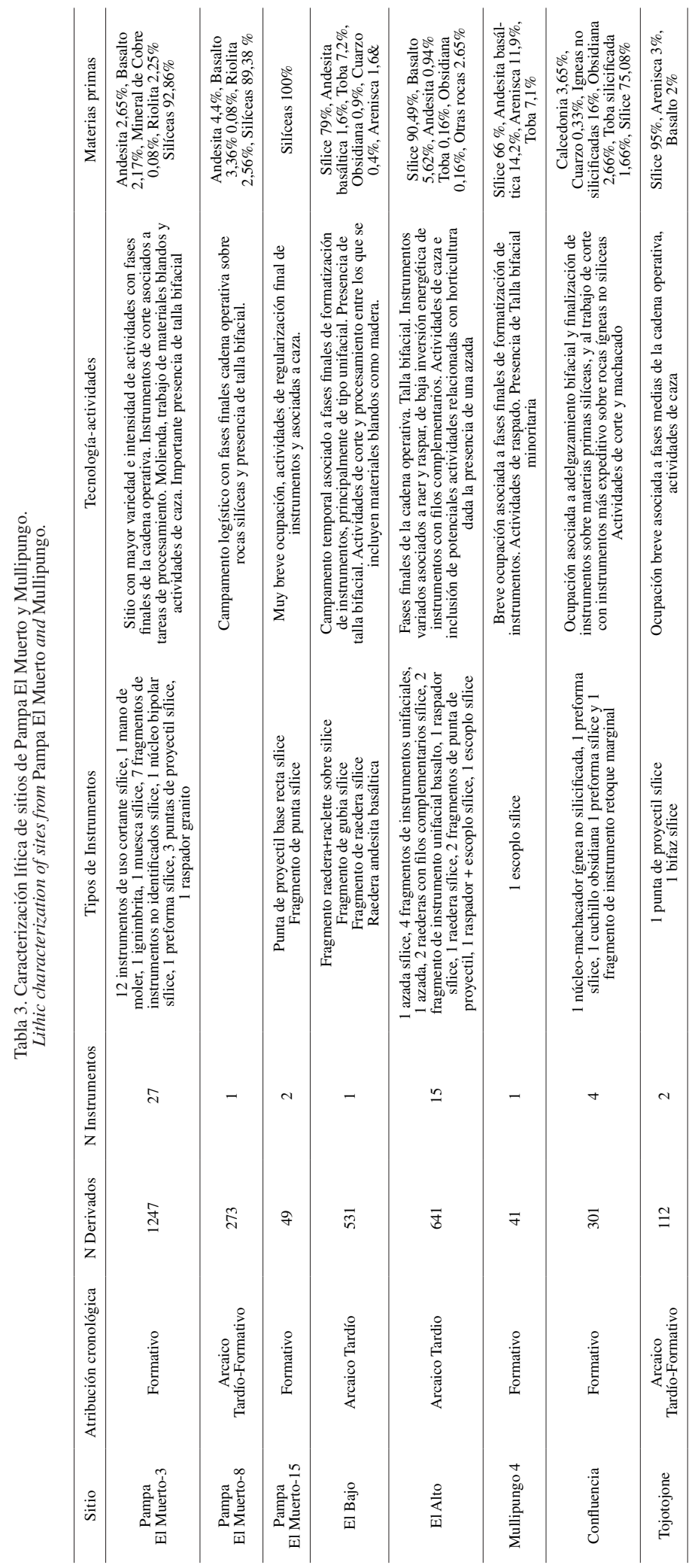



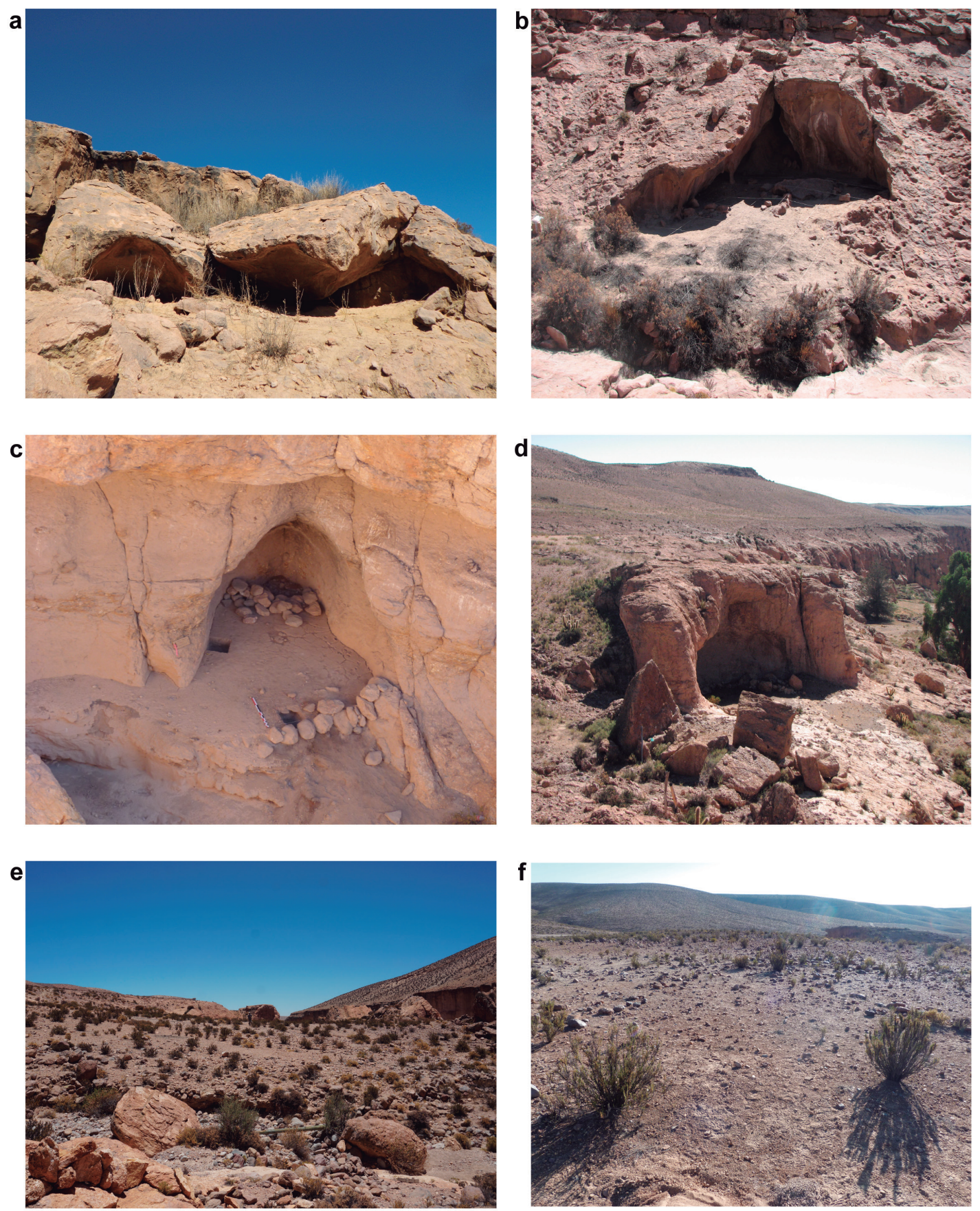

Figura 4. Ejemplos de sitios analizados en la cuenca alta del valle de Azapa: a. PM-12, b. PM-3, c. MU-4, d. MU-1, e. CNFL, f. EAL. Example of sites analysed from the upper basin of the Azapa valley: a. PM-12, b. PM-3, c. MU-4, d. MU-1, e. CNFL, f. EAL. 


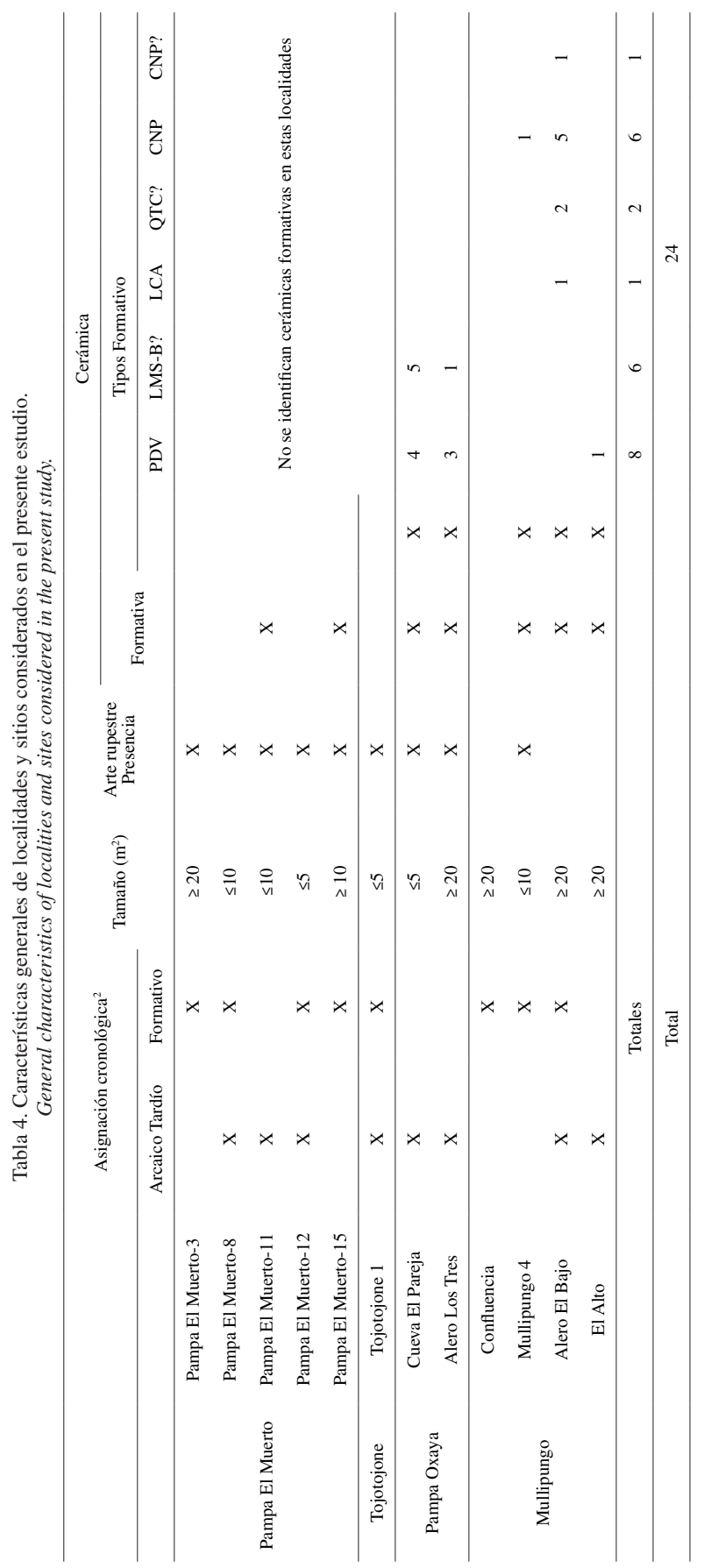


en desechos de retoque, lascas y fragmentos; mientras la andesita, la toba y la obsidiana sólo aparecen en desechos de retoque y bifaciales, identificándose instrumentos de variada inversión energética. Entre los artefactos en estratigrafía se encuentran raspadores, raederas, filos complementarios de instrumentos cortantes, instrumentos bifaciales fragmentados, una punta de proyectil, un fragmento de azada asociada a tareas agrícolas, además de lascas con retoques marginales (Llanos 2014).

Los sitios MU-4 y Confluencia de momentos formativos muestran ocupaciones breves y temporales (Figura 4). En el primero, se identifican actividades de talla relacionadas con la formatización final de instrumentos. Las materias primas seleccionadas fueron principalmente sílices (66\%), seguidas por otras andesitas $(14,2 \%)$, areniscas $(11,9 \%)$ y tobas $(7,1 \%)$. Sólo se registra un único instrumento, un escoplo (raspador de borde recto) de baja inversión de trabajo en su manufactura (Tabla 3; Almonacid 2016). El campamento abierto de Confluencia se caracteriza por desechos en sílice (75\%), de tamaños medianos y mínima corteza, indicando trabajo sobre preformas; mientras se identifica corteza en las ígneas no silicificadas, segunda materia más frecuente en el sitio (16\%). Hay obsidiana pero en muy baja frecuencia $(2,66 \%)$. Se presentan desechos de todas las categorías tecnológicas, predominando el retoque y adelgazamiento bifacial. Además de un núcleo de roca de grano medio-grueso indicativo de actividades de talla in situ, se identifica un cuchillo de obsidiana con retoque marginal y un instrumento sobre lasca de poca elaboración, probablemente usado como muesca (Tabla 4).

En resumen, se observan cambios entre las ocupaciones del Arcaico Tardío y el Formativo por cierto incremento en la diversidad de actividades identificadas. Destaca, pese la ausencia de análisis sistemáticos de vegetales, la incorporación de instrumentos asociados al trabajo agrícola y molienda desde el Arcaico Tardío como la azada en El Alto, la mano de moler en PM-3, además de un zuro de maíz en PM-15; cambios insertos dentro de espectro tecnológico donde permaneció con importancia la talla bifacial, aunque con una mayor cantidad de instrumentos de baja inversión energética presente en los sitios. Frente a estos cambios, los contextos Formativos presentan aún ocupaciones vinculadas a actividades de caza, dada la presencia de puntas de puntas de proyectil y preformas, así como también actividades de procesamiento, por la importante frecuencia de raederas e instrumentos de corte. No se observa por tanto un cambio drástico ni en el espectro de instrumentos, ni en la tecnología. No obstante, es importante destacar además que, si bien se mantuvo la utilización de rocas silíceas, en el Formativo hay una mayor frecuencia de materias primas de inferior calidad, como la andesita basáltica y la arenisca, disponibles en las distintas localidades. Todo ello pareciera indicar una reducción de los rangos de movilidad, situación que contrastaría con lo establecido para fases arcaicas anteriores con una mayor variabilidad de rocas no locales, producto de un mayor espectro de movilidad (Osorio, Capriles et al. 2017). La mayor diversidad de actividades apunta a sitios con características posiblemente más residenciales en momentos formativos por parte de grupos, no obstante, aún móviles.

\section{Cerámica Formativa en Contextos Analizados}

La cerámica contempló una caracterización macroscópica de pastas, tratamientos de superficie, formas, medidas y huellas de uso de acuerdo a una metodología probada para el norte de Chile (Uribe 2004), para cinco sitios con fragmentos atribuidos a distintas fases del Formativo regional: Cueva El Pareja y Alero Los Tres en el sector de Pampa Oxaya, y Mullipungo 4, Alero El Bajo y El Alto en el sector de Mullipungo (Tabla 4). La cerámica proviene esencialmente de aleros y de un sitio a cielo abierto (El Alto) donde se recuperó sólo un fragmento. En El Bajo, El Alto, MU-4, Alero Los Tres y El Pareja (Tabla 1), su presencia nos permite ampliar la ocupación desde el Arcaico Tardío establecida a partir de dataciones ${ }^{14} \mathrm{C}$ hasta tiempos coincidentes con el Formativo. Por otra parte, resulta interesante que en cinco casos: PM- 3, 8 y 12, así como en Tojotojone y Confluencia, se obtuvieron dataciones de ocupaciones en tiempos Formativos, pero sin cerámica (Tablas 2 y 4).

Los 24 fragmentos identificados pueden ser adscritos tanto al Formativo Temprano, como al Formativo Tardío (Figura 5). Específicamente, el componente Temprano se encuentra representado por ejemplares Pastas con Desgrasante Vegetal (PDV, $\mathrm{N}=8$ ), vinculable con los desarrollos alfareros tempranos Faldas del Morro o Azapa de los valles costeros de Arica (tipo AFM, Fernández 2011; Uribe y Ayala 2004); como también con cerámica altiplánica del mismo período, aunque característica de la cuenca Circumtiticaca y, en particular, de la cultura Chiripa (Ayala 2001; Rivas-Tello 2016; Roddick 2009). También, se identifican ejemplares Loa Café Alisado (LCA, N=1; Uribe y Vidal 2012, 2016) de Tarapacá, así como algunos posibles fragmentos Los Morros (LMS-B?, N=6; Uribe 2006) de Atacama, los Valles Occidentales y subárea Circumpuneña. Para el componente Tardío dominan los posibles ejemplares Quillagua Tarapacá Café 
Amarillento (QTC?, N=2) y Caserones Negro Pulido (CNP, $\mathrm{N}=7$ ), especialmente las piezas negras pulidas de esta última categoría (Uribe y Vidal 2012 y 2016).

La cerámica de PDV del valle de Azapa se halla en contextos con fechas que se inician en 1.120 a.C. en Azapa 71 y se extienden por la costa hacia 820 a.C. en Faldas del Morro (Ayala 2000; Fernández 2011; Uribe y Ayala 2004), otorgándole inclusive su nombre a cada tipo. Éstos se caracterizan por la presencia de antiplásticos orgánicos de naturaleza vegetal, pero también incluyen carbonatos de origen marino y fósil (Fernández 2011), articulándose con tradiciones costeras del extremo sur del Perú (Bland et al. 2017; Bolaños 2007). Aunque son escasas las dataciones por termoluminiscencia, las fechas más antiguas se encuentran en Morro 1 alrededor de 600 a.C., se documentan expresiones más tempranas en la desembocadura Camarones hacia 970 a.C. (Espoueys et al. 1995; Schiappacasse et al. 1991).

Otras expresiones de PDV se reconocen en el Altiplano Circumtiticaca, especialmente en su porción sur hasta el río Desaguadero, su principal afluente (Rivas-Tello 2016; Roddick 2009). Ahí sus primeras evidencias se remontan a los 1.660 años a.C. de acuerdo a los fechados de Quelcatani, Puno, al norte del Titicaca (Stanish 2003). Sin embargo, su desarrollo se consolida con el surgimiento de los estilos Qaluyu y Chiripa hacia 1.300-1.450 a.C., destacando este último en el sur como una tradición de PDV particular, asociada a fechas de radiocarbono tan antiguas como 1.112-822 años a.C. en Taraco (Roddick 2008, 2009). La composición de las pastas es bastante decidora, ya que en el caso altiplánico y el nuestro no se detectaron carbonatos como en la cerámica Azapa o Faldas del Morro, por lo que, preliminarmente, descartamos un origen costero para la alfarería en cuestión y, por lo mismo, sugerimos un vínculo mayor con las tierras altas.

La cerámica formativa más temprana de Tarapacá se sitúa por radiocarbono alrededor de 860 y 810 a.C. en la costa sur de Iquique (Núñez y Moragas 1983; Uribe 2009), correspondiente a alfarería Café Alisada. Esta situación sería análoga a la del interior, en plena Pampa del Tamarugal, donde se proponen fechas iniciales para la aparición de la cerámica en Tarapacá y Guatacondo, correspondientes a 950 y 806 a.C. respectivamente (Oakland 2000; Rivera 2005). Por termoluminiscencia se conocen rangos entre 730 y 530 a.C., sugiriendo fechas algo posteriores, aunque con una alfarería de Valles Occidentales ya bien desarrollada como el tipo Loa Café Alisado (Uribe y Vidal 2012, 2016). En Atacama, por su parte, la cerámica Los Morros presenta fechas de termoluminiscencia de 960 a.C. en el río Loa, aunque las asociaciones por radiocarbono la retraen hasta
1.190 a.C. en Tulan, al sur de San Pedro de Atacama (Núñez 1995; Uribe 2006). Por lo tanto, Los Morros en sus variedades A (pasta basáltica) y B (pasta granítica), es representativa de los momentos alfareros iniciales en gran parte de la subárea Circumpuneña; aunque a diferencia del tipo LCA, con un marcado carácter altoandino meridional y trasandino.

Entonces, la muestra aquí analizada se encuentra emparentada con estilos y tradiciones cerámicas diversas, aunque bastante definidas, principalmente con el Altiplano Circunlacustre y la Circumpuna atacameña en las tierras altas, así como con las tierras bajas de Tarapacá y la Pampa del Tamarugal, a la vez que más alejadas de la costa de Arica, sin descartar un nexo por completo. Además, se reconocen ejemplares de apariencia bastante temprana, sobre todo los tipos PDV, LMS y LCA; los cuales se podrían remontar a inicios del Formativo Temprano dentro de un rango aproximado entre los 1.200 y 700 años a.C. Esto sugiere un amplio radio de movilidad entre altiplano, quebradas y pampa, con el acceso a cerámica desde núcleos donde ésta ya se encontraba consolidada, más que haber sido manufacturada en la precordillera de Arica. Posteriormente, desde fines del Formativo Temprano (700-500 a.C.) en adelante pudo producirse una reducción de la movilidad y una mayor orientación hacia las tierras bajas de Tarapacá debido a cierta predominancia de la alfarería tarapaqueña, sobre todo de aquella del Formativo Tardío como los tipos QTC y CNP (200-900 d.C.).

Por su escasa cantidad y sus cualidades, los fragmentos analizados presentan características de cerámica inmersa en una dinámica de grupos cazadores recolectores (Cornejo y Sanhueza 2003). Los 24 fragmentos son muy pequeños (en el mejor de los casos apenas superan los $5 \mathrm{~cm}$ de tamaño máximo), con escasos indicadores de forma, combinando vasijas restringidas y no restringidas muy sencillas, sin poder distinguirse aún alguna forma dominante y sin mayores huellas de uso. La presencia escasa de vasijas, pequeñas y diversas tanto en formas como pastas, por lo mismo, sugiere actividades acotadas, quizás apropiadas a una movilidad todavía alta y asentamientos pasajeros o estacionales. Desde esta perspectiva, la alfarería no tendría un lugar protagónico en la vida doméstica, sino que bastante acotado, aludiendo a un uso eventual.

Coincidentemente, se ha señalado que la predilección de piezas elaboradas con material vegetal denota cierto interés por su plasticidad resistente al movimiento y liviandad para su transporte (Fernández 2011; Skibo y Schiffer 1995; Skibo et al. 1989). Adicionalmente, la combinación de piezas con desgrasante vegetal y otras con antiplástico mineral (p.ej., LMS) se asociaría a una cocción diferencial 
a
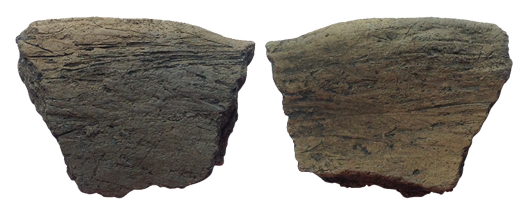

$1 \mathrm{~cm}$

d
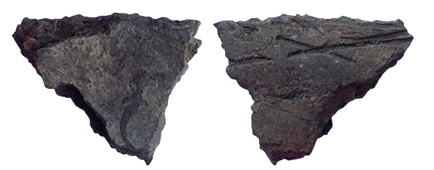

$1 \mathrm{~cm}$

b

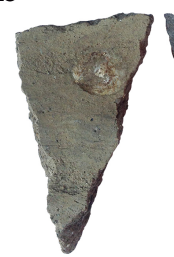

e

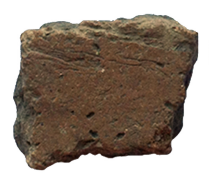

g

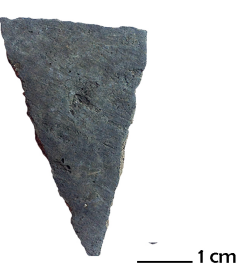

c
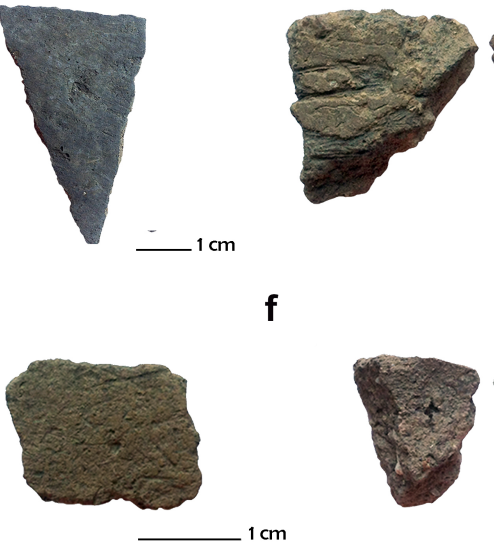

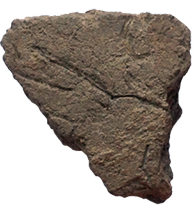

$1 \mathrm{~cm}$

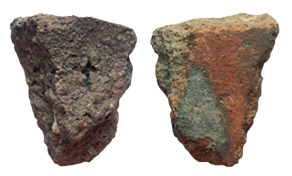

$1 \mathrm{~cm}$

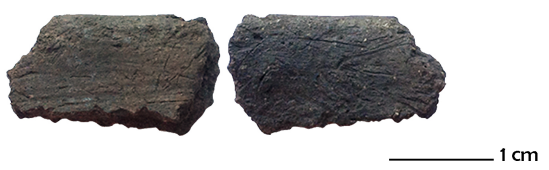

h
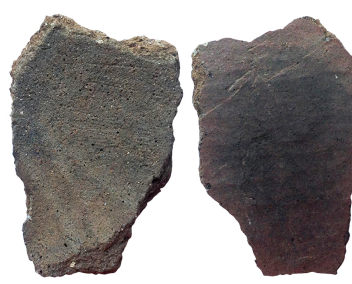

$-1 \mathrm{~cm}$

j

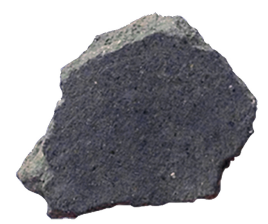

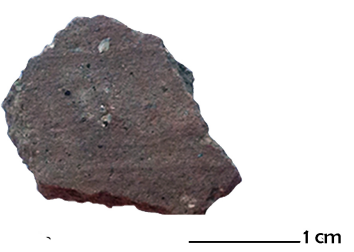

i
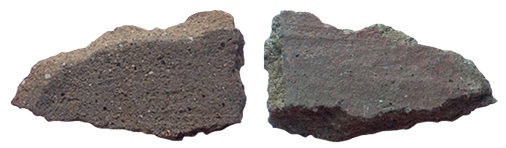

$\mathbf{k}$
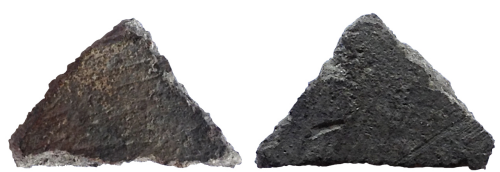

$1 \mathrm{~cm}$

Figure 5. Cerámica formativa de la cuenca alta del valle de Azapa. Tipo PDV: a. CEP, U1-1a; b. CEP, U1-1a; c. ATR, U4-1a; d. CEP, U2-4c; e. ATR, U8-1c; f. ATR, U4-1a; g. CEP, U3e-1a; Tipo LCA: h. CEP, U1-1a; i. CEP, U1-1a.; Tipo LMS: j. CEP, U3-1a; k. ATR, U8-1d.

Formative ceramic from the upper basin of the Azapa valley. Type PDV: a. CEP, U1-1a; b. CEP, U1-1a; c. ATR, U4-1a; d. CEP, U2-4c; e. ATR, U8-1c; f. ATR, U4-1a; g. CEP, U3e-1a; Type LCA: h. CEP, U1-1a; i. CEP, U1-1a.; Type LMS: j. CEP, U3-1a; $k$. ATR, U8-1d. 
de alimentos vegetales: las primeras mejor para la cocción de plantas C3 (p.ej., granos y tubérculos silvestres o semi domesticados); mientras que las segundas, apropiadas para plantas domesticadas C4 (p.ej., maíz), (Roddick 2009; Steadman 1995). Así los grupos pudieron estar experimentando tanto con plantas nuevas, así como con formas de preparación novedosas, por lo que estarían conociendo y accediendo a vasijas distintas. Por lo mismo, tampoco es extraño que consideren un amplio espectro de surtidores de plantas y vasijas, incluidos aquellos con mayor experiencia agrícola de las tierras bajas de Tarapacá que ofrecen vasijas para almacenar y consumir alimentos líquidos (Uribe y Vidal 2016).

\section{Registros Faunísticos en Tiempos Arcaico Tardío y Formativos}

El análisis arqueozoológico consistió en la identificación, cuantificación, y caracterización ${ }^{3}$ de los restos óseos. Dada su naturaleza fragmentaria y el estado de avance de la investigación en la zona de estudio aún no se efectúan los análisis osteométricos y morfométricos para estimar la variabilidad de las especies de camélidos -siendo los principales índices para discutir procesos de amansamiento de los animales-, y el perfil etario de la muestra. No obstante, mediante la frecuencia de los restos y las modificaciones antrópicas abordamos cambios y continuidades en registro faunístico a lo largo del tiempo. Se analizaron 6.750 restos óseos animales, 4.020 corresponden a contextos atribuibles al Arcaico Tardío y 2.730 a contextos ubicados cronológicamente en el Formativo (Tabla 5). La mayor variabilidad taxonómica se registró en los niveles Arcaico Tardío de El Bajo, con fragmentos óseos de camélidos, aves, roedores, felinos, escualo (un diente), Lagidium peruanum (vizcacha) e Hippocamelus antisensis (Taruka), estas últimas dos especies también se hallaron en los sitios PM-8 (Arcaico Tardío y Formativo) y PM-3 (Formativo) (Tabla 5).

En cuanto a las partes esqueletales de las carcasas de camélidos, no se reportan diferencias sustanciales entre los contextos del Arcaico Tardío y los del Formativo. En ambos hay una predominancia de fragmentos de vértebras y costillas, seguido de segmentos de esqueleto apendicular como fémur, tibia y metapodio. Esto indica que el consumo y descarte de los animales se mantuvo en ambos períodos, aunque con ligeras variaciones de frecuencia de cada parte.

La preservación óptima de la superficie ósea se registró en un $85 \%(n=5.737)$ del total de los fragmentos analizados, permitiendo señalar sin inconvenientes que procesos tafonómicos de erosión, corrosión, diagénesis, e intervenciones de plantas $\mathrm{y}$ animales no afectaron mayormente la estructura del registro óseo animal (Tabla 5). Los análisis de termoalteraciones y modificaciones antrópicas se efectuaron esencialmente sobre los restos óseos atribuibles a camélidos, también de modo de poder evaluar el patrón de consumo a lo largo del tiempo. La mayor cantidad de restos de camélidos proviene desde los contextos arcaicos tardíos (NISP: 280), siendo más acotados para los formativos (NISP: 103).

En general en todos los sitios, la proporción de restos termoalterados es baja, remitiéndose a quema inicial y a calcinación final, siendo mayor su número en contextos Arcaico Tardío ( $\mathrm{N}=93$ ) frente a los Formativos (N=29). El empleo de los animales como combustible (además de la posible preparación de los restos al fuego) fue una práctica constante en el tiempo, aunque varió en sus proporciones. Se registraron 93 fragmentos óseos con evidencias de modificaciones antrópicas (huellas de cortes, fracturas intencionales y lascas), además de cuatro fragmentos de artefactos óseos (Tabla 5). La mayoría se concentra en los contextos del Arcaico Tardío ( $\mathrm{N}=77$ y tres fragmentos de artefactos), mientras disminuye para los Formativos ( $\mathrm{N}=16$ y un fragmento de artefacto). La naturaleza de las modificaciones antrópicas se distribuye de manera similar en los dos momentos, pues en ambos predominan las fracturas helicoidales sobre los huesos, seguidas de las lascas óseas y finalmente las huellas de corte. Sin embargo, existen ligeras variaciones en cuanto a sus proporciones: para el Arcaico Tardío las fracturas helicoidales alcanzan 52 fragmentos, 22 lascas y tres fragmentos con huellas de corte; mientras que para el Formativo las fracturas helicoidales suman 10, cinco lascas óseas $\mathrm{y}$ un fragmento con huellas de corte. Respecto a los artefactos también son más variados para el Arcaico Tardío: 1 Retocador de asta de Taruka, una cuenta ósea tubular y un fragmento de cuenta ósea plana; mientras para el Formativo se registra un fragmento de hueso plano y borde denticulado (Tabla 5).

Con los resultados obtenidos y los parámetros analizados, podemosevaluartreselementos vinculados al tipo de relación sostenida entre las poblaciones de la precordillera y la fauna, esencialmente los camélidos: transporte de presas a los sitios, su procesamiento y preparación. En general, podemos señalar que no existen diferencias sustanciales entre los contextos del Arcaico Tardío y los del Formativo, en torno a qué presas ingresaban a los sitios, cómo las preparaban, las consumían y las descartaban. Las variaciones surgen respecto a cambios en la frecuencia de la 


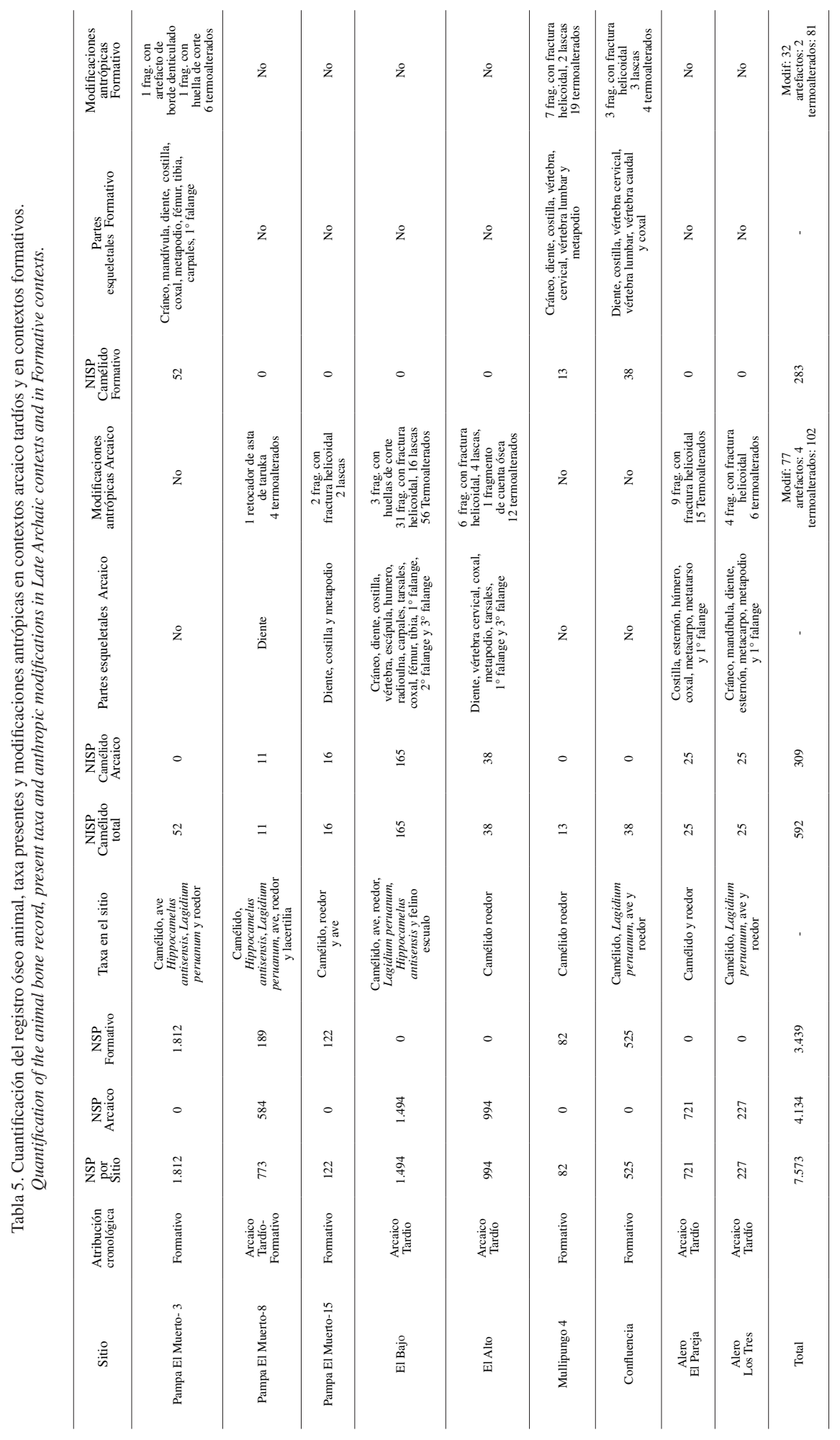


cantidad de restos óseos y de las modificaciones antrópicas, lo que puede también relacionarse con un problema de muestreo. No obstante, aunque existan cambios sutiles, el consumo de camélidos y el vínculo establecido entre animales y humanos no presenta cambios significativos entre los contextos Arcaico Tardío y Formativo. Así pese a posiblemente introducirse cambios en la gestión de los animales (pastoreo), la caza, uso y consumo de camélidos se mantuvieron en el tiempo.

\section{Discusión}

Las dataciones presentadas permiten enunciar, pese a problemas que podrían estar relacionados con el muestreo, tipo de sitios y selección de estratos datados, cierta continuidad ocupacional de la precordillera, desde cal. 4.900 a.C. hasta 650 d.C., aunque con momentos que hoy aparecen con menor expresión. En términos de funcionalidad de sitios, para el Arcaico Tardío la mayoría presenta eventos ocupacionales breves y temporales, asociados a actividades de talla lítica, preparación de variados instrumentos, junto al consumo de recursos animales, principalmente camélidos (ver también Osorio et al. 2016; Santoro et al. 2016; Sepúlveda et al. 2013). Para los sitios cuyas dataciones coinciden con el Formativo se reconocen variadas situaciones, con ocupaciones también acotadas: aleros sin cerámica cuyas ocupaciones perpetúan de alguna forma la función y tipo de actividades evidenciadas para el Arcaico Tardío, (PM-8 y Tojotojone); otros de similares características, pero con cerámica (MU-4), además de un sitio a cielo abierto (El Alto); $\mathrm{y}$ aleros que presentan ocupaciones con una mayor diversidad de actividades y sin cerámica (PM-3 y 15). El Bajo constituye un caso excepcional por la mayor diversidad de actividades y la presencia de fragmentos cerámicos formativos $(\mathrm{N}=9)$, aunque esta visión debe plantearse con cautela por los problemas estratigráficos del sitio.

En síntesis, el registro material presentado indica la existencia de cambios en las ocupaciones precordilleranas asociadas a una mayor diversidad de actividades en los sitios, incluida la molienda y por ende una nueva forma de consumo de vegetales, junto al uso de cerámica, además de objetos misceláneos foráneos (Castillo y Sepúlveda $2015,2017)$, ambos obtenidos vía intercambio y conexiones con variadas regiones, al menos a partir del Formativo Temprano, con grupos propiamente alfareros, posiblemente de la Costa, pero también de Tierras Altas. Sin descartar que su obtención se inserte dentro de otras actividades económicas, también pudieron obtenerse dentro de prácticas simbólicas considerando, especialmente, la relación de estos sitios con manifestaciones de pinturas rupestres (Sepúlveda et al. 2017). Cabe recordar que una de las posibilidades de la aparición de la cerámica es que haya surgido o fuera incorporada en contextos sociales de alta competencia social y ritual dentro de cazadores recolectores (Dietler y Hayden 2001; Politis et al. 2004; Vitelli 1999). En consecuencia, nos parece que estamos frente a poblaciones cazadoras recolectoras alto andinas que se encuentran participando de procesos propios del Formativo, pero sin ser propiamente productoras de alfarería, situación probablemente generalizada en la precordillera, al informarse de cerámica (fragmentos PDV) en Hakenasa y Piñuta, del valle de Lluta, con fechas entre los $2.850 \pm 200$ y $2.520 \pm 90$ años a.p. (Santoro 1989:47, 51), situación distinta a la propuesta por Schiappacasse y Niemeyer previamente (1996). Los bienes foráneos y misceláneos pueden también ser interpretados producto de cambios en las prácticas sociales de estos grupos como en sus formas de organización social, al ser esencialmente bienes ornamentales (Castillo y Sepúlveda 2015, 2017).

El tamaño de los eventos de ocupación, la escasa cantidad de cerámica, morteros o manos de moler, la disminución en la variedad de rocas locales utilizadas, y el arte rupestre empleado como marcador territorial (Sepúlveda et al. 2017) son interpretados a partir de una reducción en los rangos de movilidad. Indicadores que pueden entonces ser comprendidos dentro de un patrón de ocupación más permanente y recurrente de la precordillera en términos temporales por parte de grupo aún móviles, con cambios paulatinos que coinciden con transformaciones en los patrones de asentamiento en las regiones vecinas que apuntan hacia una cada vez mayor concentración y congregación poblacional, y una mayor territorialidad desde el Arcaico Tardío (Craig 2012; Standen et al. 2014). $\mathrm{El}$ arte rupestre muestra además una nueva forma de relación con los camélidos, mediante su captura en vida y, por ende, un manejo diferente de los mismos, pese a mantenerse la caza, aspecto interpretado a partir de la superposición de un tipo de escena sobre otra e inversamente (Dudognon y Sepúlveda 2016).

Estos cambios ocurren sin embargo dentro de un espectro de continuidades como son la mantención de la tecnología lítica con una talla bifacial aún importante, junto con la preferencia por rocas silíceas. Asimismo, las actividades de caza, consumo y descarte de los camélidos también tienden a conservar durante el Formativo un patrón similar a lo que ocurre en el Arcaico Tardío. Así, estos grupos alto andinos aún móviles habrían incorporado el 
manejo de animales domesticados -pese a no registrarse corrales-, y plantas, dinámicas semejantes señaladas para los grupos formativos tempranos del Altiplano, la Circumpuna, Tarapacá y el Loa (p.ej., Gallardo y Uribe 2008; Núñez 1995; Núñez y Santoro 2011; Roddick 2008, 2009; Uribe 2006; Uribe y Vidal 2012).

$\mathrm{Si}$ bien todos estos elementos dan cuenta de cambios en ciertas prácticas, creemos que no pueden ser utilizados como sinónimo de lo que conocemos clásicamente como Formativo, a no ser que entendamos este período como un lapso heterogéneo, de límites variables, durante el cual coexistieron grupos con distintos modos de vida y de producción. Es sugerente, en este sentido, que en tres distintas localidades vecinas de la cuenca del lago Titicaca se identifiquen procesos de cambios en las fases finales del Arcaico Tardío, con intensidades y ritmos variados diferentes (Aldenderfer 2002), pues pareciera indicar que ya en esos momentos grupos cercanos pudieron adoptar, así como modificar ciertas prácticas, generando de esta manera trayectorias históricas locales y propias, difíciles de definir con una sola etiqueta.

\section{Palabras Finales}

Los cazadores-recolectores de la precordillera del extremo norte de Chile fueron entonces agentes activos de su historia, entre 1.500 a.C. y 650 d.C., cuando grandes cambios ocurrían en regiones vecinas; agentes activos, porque los cambios no fueron asimilados de manera homogénea ni sincrónica, sino que incorporados dentro de sus propias dinámicas (Ingold 2000).
Los resultados aquí presentados junto con dar cuenta de ocupaciones previamente poco visibilizadas, definen una trayectoria histórica distinta dentro del área Centro-Sur andina. Sin embargo, es necesario ahondar aún más en las particularidades de estos procesos también en las distintas cuencas de la región -al no haber por ejemplo cerámica formativa en todos los sectores aquí estudiados-, pero también de la sierra sur del Perú donde similitudes estilísticas en el arte rupestre sugieren la construcción de un paisaje y territorio común con la precordillera del extremo norte de Chile en estos tiempos (Sepúlveda et al. 2017). Indagar en estas diversas trayectorias formativas de grupos que mantuvieron su movilidad y modo de vida en la precordillera, pese a incorporar nuevos recursos e interactuar con otros grupos sedentarios, alfareros, agrícolas y pastoriles, nos permitirá además comprender mejor el sustrato de las ocupaciones tardías de esta región, donde aún permanece un vacío entre 650 y 1.100 d.C.

Agradecimientos: Trabajo financiado por proyecto FONDECYT 1130808 y realizado con el apoyo del Convenio de Desempeño UTA-MINEDUC. Agradecemos a las comunidades de Tignamar y Belén, en particular Merita Huanca y Adela Cutipa por recibirnos siempre tan cordialmente; así como a todos los profesionales y estudiantes de las Universidades de Tarapacá, de Chile y Alberto Hurtado por compartir experiencias precordilleranas entre 2013 y 2015. Finalmente, nuestros reconocimientos a los evaluadores anónimos que contribuyeron a mejorar sustancialmente con sus comentarios la versión original de este trabajo.

\section{Referencias Citadas}

\begin{abstract}
Aldenderfer, M. 1989. The Archaic Period in the South-Central Andes. Journal of World Prehistory 3:117-158.

Aldenderfer, M. 1998. Montane Foragers. Asana and the SouthCentral Andean Archaic. University of Iowa Press, Iowa City.

Aldenderfer, M. 2001. Continuity and change in ceremonial structures at late preceramic Asana, southern Peru. Latin American Antiquity 2:227-258.

Aldenderfer, M. 2002 Explaining changes in settlement dynamics across transformations of modes of production: from hunting to herding in south-central Andes. En Beyond Foraging and Collecting: Evolutionary Change in Hunter-Gatherer Settlement Systems, editado por B. Fitzhugh y J. Habu, pp. 387-412. Springer, Nueva York.

Aldenderfer, M. 2010. Gimme that old time religion: Rethinking the role of religion in the emergence of social inequality. En Pathways to Power, editado por T.D. Price y G.M. Feinman, pp.77-94. Springer, Verlag New York.
\end{abstract}

Almonacid, F. 2016. Tecnología y Aprovisionamiento Lítico durante la Transición Arcaico-Formativo en la Precordillera de Arica (Norte de Chile). Memoria de Título profesional de Arqueólogo, Universidad de Tarapacá, Arica.

Andrefsky, W. 2005 Lithic: Macroscopic Approaches to Analysis. Cambridge University Press, Cambridge.

Ayala, P., 2001. Las sociedades formativas del Altiplano Meridional y su relación con el Norte Grande de Chile. Estudios Atacameños 21:7-39.

Ballester, B. y F. Gallardo 2011. Prehistoric and historic networks on the Atacama Desert coast (northern Chile). Antiquity 85:875889.

Behrensmeyer, A. 1978. Taphonomic and Ecologic Information from Bone Weathering. Paleobiology 4 (2):150-162.

Binford, L. 1980. Willow Smoke and Dog's Tail. Hunther-Gatherer Settlement Systems and Archaeological Site Formation. American Antiquity 45 (1):4-20. 
Bland, C., A. Roberts, R. Popelka-Filcoff, C. Santoro, C. Carter, J. Bennett y A. Topic 2017. 1500 years of pottery: Neutron activation analysis of northern Chilean domestic ceramics from Caleta Vitor and clay samples from nearby valley and highland contexts. Archaeometry 59:815-833.

Blumenschine, R. 1995. Percussion marks, tooth marks, and experimental determinations of the timing of hominid and carnivore access to long bones at FLK Zinjanthropus, Olduvai Gorge, Tanzania. Journal of Human Evolution 29:21-51.

Blumenschine, R., C. Marean y S. Capaldo 1996. Blind tests of inter-analyst correspondence and accuracy in the identification of cu marks, percussion marks and carnivore tooth marks on bone surfaces. Journal of Archaeological Science 23:493-507.

Bolaños, A. 2007. El Cañón, un sitio del Formativo Temprano en el litoral de Tacna, Perú. Tesis para optar el título profesional de Licenciado en Arqueología. E.A.P. de Arqueología, Facultad de Ciencias Sociales, Universidad Nacional Mayor de San Marcos, Lima.

Castillo, C. y M. Sepúlveda 2015. ¿Movilidad o interacción?: objetos "no-utilitarios" en contextos Arcaico Tardío del extremo norte de Chile. Actas del XIX Congreso Nacional de Arqueología Chilena, pp. 161-172. Universidad de Tarapacá Ediciones, Arica.

Castillo, C. y M. Sepúlveda 2017. Objetos "misceláneos" y dinámicas sociales en contextos cazadores recolectores de la Precordillera de Arica, norte de Chile (área Centro- Sur andina). Chungara Revista de Antropología Chilena 49:159-174.

Cornejo, L. y L. Sanhueza 2003. Coexistencia de cazadores recolectores y horticultores tempranos en la cordillera andina de Chile Central. Latin American Antiquity 14 (4):389-407.

Craig, N. 2005. The Formation of Early Settled Villages and the Emergence of Leadership: A Test of Three Theorical Models in the Río Ilave, Lake Titicaca Basin, Southern Peru. Thesis for the degree of Doctor of Philosophy in Anthropology, University of California, Santa Barbara.

Craig, N. 2011. Cultural dynamics, climate, and landscape in the South-Central Andes during the mid-late Holocene: A consideration of two socio-natural perspectives. Chungara Revista de Antropología 43:367-391.

Craig, N. 2012. Transiciones del Arcaico Tardío al Formativo Temprano. Una perspectiva desde la arqueología de la unidad doméstica en dos sitios del valle del río Ilave, cuenca del Lago Titicaca. En Arqueología de la Cuenca del Titicaca, Perú, editado por L. Flores Blanco y H. Tantaleán, pp.41-130. Instituto Francés de Estudios Andinos, Lima.

Craig, N., M. Aldenderfer, P. Baker y C. Rigsby 2010. Terminal archaic settlement pattern and land cover change in the río Ilave, southwestern Late Titicaca basin, Peru. En The Archaeology of Anthropogenic Envirnoments, editado por R.M. Dean, pp. 5-53. Southern Illinois University, Illinois.

De Nigris, M. 2005. De fracturas y otros huesos. Consumo de médula en Patagonia Meridional. Actas de XIII Congreso nacional de arqueología Argentina, pp.109-116, Córdoba.

Diaz-Zorita, M., D. Drucker, P. Richardin, V. Silva-Pinto, M. Sepúlveda y H. Boscherens 2016. Marine food consumption in coast northern Chilean (Atacama Desert) population during the Formative Period: Implication of isotopic evidence $(\mathrm{C}, \mathrm{N}$, S) for Neolithic process in south central Andes. Journal of Archaeological Science Reports 6:768-776.
Dietler, M. y B. Hayden 2001. Feats: Archaeological and Ethnographic Perspectives on Food, Politics, and Power. Smithsonian Institution Press, Washington D.C.

Dillehay, T. 2014. Sedentarismos y complejidad prehispánicos en América del Sur. Intersecciones en Antropología 14:29-65.

Dudognon, C. y M. Sepúlveda 2016. Rock art of the upper Lluta valley, northernmost of Chile (South Central Andes): A visual approach to socio-economic changes between Archaic and Formative periods (6,000-1,500 years BP). Quaternary International. http://dx.doi.org/10.1016/j.quaint.2016.10.009

Espoueys, O., M. Uribe, A. Román y A. Deza 1995. Nuevos fechados por termoluminiscencia para la cerámica del período Medio del valle de Azapa ( $1^{\text {a }}$ Parte). Actas del XIII Congreso Nacional de Arqueología Chilena, Tomo II:31-54. Universidad de Antofagasta -SCHA, Antofagasta.

Fernández, M.S. 2011. Modelando en Arcilla: Aproximaciones a la Producción y el Consumo de Cerámica durante el Periodo Formativo de los Valles Costeros del Norte de Chile (1400 a.C.500 d.C.). Tesis para optar al grado de Doctor en Antropología. Programa de Doctorado en Antropología, Universidad de Tarapacá, Arica

Flores Blanco, L. 2014. El surgimiento del paisaje monumentalizado en la cuenca del lago Titicaca, Andes Centro-Sur. Complutum 25:47-71.

Focacci, G. 1974. Excavaciones en el Cementerio Playa Miller-7, (Arica) Chile. Chungara 3:23-74.

Gallardo, F., B. Ballester y N. Fuenzalida 2017. Monumentos Funerarios de la Costa del Desierto de Atacama: Contribuciones al Intercambio de Bienes e Información entre CazadoresRecolectores Marinos (Norte de Chile). ICIIS \& SCHA, Santiago, en prensa.

Gallardo, F. y P. De Souza 2008. Rock art, modes of production, and social identities during the early Formative period in the Atacama Desert (northern Chile). En Archaeologies of Art. Time, Place and Identity, editado por I.D. Sanz, D. Fiore y S.K. May, pp.79-97. Left Coast Press, Walnut Creek California.

García, M. y M. Sepúlveda 2011. Contextos vegetales asociados a aleros pintados de la Precordillera de Arica (extremo norte de Chile). Estudios Atacameños 41:97-118.

García, M., A. Vidal, V. Mandakovic, A. Maldonado, M.P. Peña y E. Belmonte 2014. Paleoambiente en las aldeas formativas de la Pampa del Tamarugal, Tarapacá (ca. 900 AC- 800 DC) Estudios Atacameños 47:33.58.

Gayó, E., C. Latorre y C. Santoro 2015. Timing of occupation and regional settlement patterns revealed by time-series analyses of an archaeological radiocarbon database for the South-Central Andes $\left(16^{\circ}-25^{\circ} \mathrm{S}\right)$. Quaternary International 356:4-14.

Gnecco, C. y C.H. Langebaek 2006. Contra la tiranía del pensamiento tipológico. En Contra la Tiranía Tipológica en Arqueología: Una Visión desde Suramérica, editado por C. Gnecco, C.H. Langebaek, pp.IX-XIV. Universidad de los Andes, Ediciones Uniandes, Bogotá.

Grayson, D. 1984. Quantitative Zooarchaeology. Academic Press, Orlando.

Hastorf, C. 2008. The Formative period in the Titicaca Basin. En Handbook of South American Archaeology, editado por H. Silverman y W.H. Isbell, pp. 545-561. Springer, New York. 
Hocsman, S. 2002. ¿Cazadores recolectores complejos en la Puna Meridional Argentina? Entrelazando evidencias del registro arqueológico de la microrregión de Antofagasta de la Sierra (Catamarca). Relaciones de la Sociedad Argentina de Antropología XXVII:193-214.

Isaac, G. 1967. Toward the interpretation of occupational debris: some experiments and observations. Kroeber Anthropological Society Papers 37:31-57.

Johnson, E. 1985. Current Developments in Bone Technology. En Advances in Archaeological Method and Theory, editado por M. Schiffer, pp.157-235. Academic Press, New York.

Lavallée, D. 2006 Secuencias y consecuencias de algunos procesos de neolitización en Los Andes Centrales. Estudios Atacameños 32:35-41.

Llanos, C. 2014. Actividades de los Cazadores Recolectores del Arcaico Tardío en la Precordillera de Arica: Análisis Tecnológico Lítico del Sitio El Alto, Sector de Mullipungo- Tignamar. Memoria de Título profesional de Arqueólogo, Universidad de Tarapacá, Arica.

Lumbreras, L. 2006. Un Formativo sin cerámica y cerámica preformativa. Estudios Atacameños 32:11-34.

Lyman, R. 1994. Vertebrate Taphonomy. University Press, Cambridge.

Marquet, P., C. Santoro, C. Latorre, V. Standen, S. Abades, M. Rivadeneira, B. Arriaza y M. Hochberg 2012. Emergence of social complexity among coastal hunter-gatherers in the Atacama Desert of northern Chile. Proceedings of the National Academy of Sciences 109:14754-14760.

Muñoz, I. 2004. El período Formativo en los valles del norte de Chile y sur del Perú: nuevas evidencias y comentarios. Chungara Revista de Antropología Chilena Vol. Especial, Tomo I, pp. 213-225.

Muñoz, I., C. Agüero y D. Valenzuela 2016. Poblaciones prehispánicas de los Valles Occidentales del norte de Chile: desde el período Formativo hasta el Intermedio Tardío (ca. 1.000 a.C. a 1.400 d.C.). En Prehistoria en Chile. Desde sus Primeros Habitantes hasta los Incas, editado por F. Falabella, M. Uribe, L. Sanhueza, C. Aldunate y J. Hidalgo, pp.181-238. Editorial Universitaria, Santiago.

Nelson, M. 1991. The study of technological organization. Archaeological Method and Theory 3:57-100.

Núñez, L. 1989. Hacia la producción de alimentos y la vida sedentaria (5000 a.C. a 900 d.C.). En Culturas de Chile, Prehistoria, Desde sus Orígenes Hasta los Albores de la Conquista, editado por J. Hidalgo, V. Schiappacasse, H. Niemeyer, C. Aldunate e I. Solimano, pp.81-106. Editorial Andrés Bello, Santiago.

Núñez, L., I. Cartajena, C. Carrasco, P. López, P. De Souza, F. Rivera y B. Santander 2017. Presencia de un centro ceremonial formativo en la Circumpuna de Atacama. Chungara Revista de Antropología Chilena 49:3-33.

Núñez, L., I. Cartajena, C. Carrasco y P. De Souza 2006. El Templete Tulán de la Puna de Atacama: emergencia de complejidad ritual durante el Formativo Temprano (norte de Chile). Latin American Antiquity 17:445-473

Núñez, L., I. Cartajena, C. Carrasco, P. De Souza y M. Grosjean 2006. Emergencia de comunidades pastoralistas formativas en el sureste de la Puna de Atacama. Estudios Atacameños 32:93-117.

Núñez, L. y C. Moragas 1983. Cerámica temprana en Cáñamo (costa desértica del norte de Chile): Análisis y evaluación regional. Chungara 11:31-61.
Nuñez, L. y C. Santoro 2011. El tránsito Arcaico-Formativo en la circumpuna y valles occidentales del centro sur andino: hacia los cambios "neolíticos". Chungara Revista de Antropología Chilena 43:487-530.

Oakland, A. 2000. Andean textiles from village and cemetery: Caserones in the Tarapacá valley, northern Chile. En Beyond Cloth and Cordage, Archaeological Textile Research in the Americas, editado por P. Drooker e I. Webster, pp.229-251. The University of Utah Press, Salt Lake City.

Osorio, D. J. Capriles, P. Ugalde, K. Herrera, M. Sepúlveda, E. Gayó, C. Latorre, D. Jackson y C. Santoro 2017. HunterGatherer Mobility Strategies in the High Andes during the Late Pleistocene Holocene transition (ca.11,500-9,500 cal yr BP)". Journal of Field Archaeology 42 (3):228-240.

Osorio, D., M. Sepúlveda, C. Castillo y M. Corvalán 2016. Análisis lítico y funcionalidad de sitios de los aleros de la Precordillera de Arica (Centro-Sur andino) durante el período Arcaico (ca. 10.0003.700 años A.P.). Intersecciones en Antropología 17:77-90.

Osorio, D., J. Steele, M. Sepúlveda, E. Gayó, J. Capriles, K. Herrera, P. Ugalde, R. de Pol- Holz, C. Latorre y C. Santoro 2017. The Dry Puna as an ecological megapatch and the peopling of South America: Technology, mobility, and the development of a late Pleistocene/early Holocene Andean hunter-gatherer tradition in northern Chile. Quaternary International. http://dx.doi. org/10.1016/j.quaint.2017.07.010

Pacheco, V., A. Altamirano y E. Guerra 1979. Guía Osteológica de Camélidos Sudamericanos. Universidad Nacional Mayor de San Marcos, Lima.

Politis, G. 1996. Moving to produce: Nukak mobility and settlement pattern in Amazonia. World Archaeology 27(3):492-511.

Politis, G.P. Messineo, C. Kaufmann, M. Barros, M. Álvarez, V. Di Prado y R. Scalise 2004. Persistencia ritual entre cazadores recolectores de la llanura pampeana. Boletín de Arqueología PUCP 9:67-90.

Santana, F., M. Uribe, M.J. Herrera, R. Retamal y S. Flores 2015. Brief communication. Diet practices in ancient populations from northern Chile during the transition to agriculture (Tarapacá region, 1000 BC- AD900). American Journal of Physical Anthropology 158:751-758.

Santoro, C. 1989. Antiguos Cazadores de la Puna (9.000 a 6.000 A.P.). En Culturas de Chile, Prehistoria, Desde sus Orígenes Hasta los Albores de la Conquista, editado por J. Hidalgo, V. Schiappacasse, H. Niemeyer, C. Aldunate e I. Solimano, pp.3355. Editorial Andrés Bello, Santiago.

Santoro, C. y J. Chacama 1984. Secuencia de asentamientos precerámicos del extremo norte de Chile. Estudios Atacameños 7:71-84.

Santoro, C., D. Osorio, P. Ugalde, M. Sepúlveda, I. Cartajena, V. Standen, E. Gayó, A. Maldonado, M. Rivadeneira, C. Latorre, B. Arriaza, F. Rothhammer, P. De Souza, C. Carrasco y L. Núñez 2016. Cazadores recolectores y pescadores Arcaicos del desierto de Atacama. Entre el Pacífico y los Andes. Norte de Chile (ca. 10.000-3.700 A.P.). En Prehistoria en Chile: desde sus Primeros Habitantes hasta los Incas, editado por F. Falabella, M. Uribe, L. Sanhueza, C. Aldunate y J. Hidalgo, pp.117-180. Editorial Universitaria, Santiago.

Santoro, C., D. Osorio, V. Standen, P. Ugalde, K. Herrera, E. Gayó, F. Rothhammer y C. Latorre 2011 (publicado 2013). Ocupaciones humanas tempranas y condiciones paleoambientales en el Desierto de Atacama durante la transición Pleistoceno-Holoceno. Boletín de Arqueología PUCP 15:295-314. 
Santoro, C., V. Standen y B. Arriaza 2001. ¿Patrón funerario Arcaico o alteración postdeposicional?: el enterratorio de Patapatane en los Andes Centro Sur. Chungara Revista de Antropología Chilena 33:43-49.

Schiappacasse, V. y H. Niemeyer 1996. Las pictografías de los aleros de Itiza y de Mullipungo de la Sierra de Arica. Chungara 28(1-2):253-276.

Sepúlveda, M., D. Osorio, L. Cornejo, T. Saintenoy, L. Sitzia y F. Espinoza 2018. Highland archaic mobilities re-visited (cal. $10.500-3.500$ years B.P.). A meso-scale study in the upper basin of the Azapa Valley, northernmost Chile (Atacama Desert). Manuscrito en poder de los autores.

Sepúlveda, M., M. García, E. Calás, C. Carrasco y C. Santoro 2013. Pinturas rupestres y contextos arqueológicos de la Precordillera de Arica (Extremo norte de Chile). Estudios Atacameños 46:27-46.

Sepúlveda, M., T. Saintenoy, L. Cornejo, C. Dudognon, F. Espinoza, Z. Guerrero y E. Cerrillo 2017. Rock Art Painting and Territoriality in the Precordillera of Arica, Northern Chile (South Central Andes). Archaeological and Spatial Approaches for the Naturalistic Tradition. Quaternary International. http:// dx.doi.org/10.1016/j.quaint.2017.02.005

Sierpe, V. 2015. Atlas Osteológico del Guanaco (Lama guanicoe). Ediciones Universidad de Magallanes, Punta Arenas.

Silva-Pinto, V., D.C. Salazar-García e I. Muñoz 2014. Una aproximación a la dieta consumida por las poblaciones constructoras de túmulos. En Mil Años de Historia de los Constructores de Túmulos en los Valles Desérticos de Arica: Paisaje, Monumentos y Memoria, editado por Muñoz, I. y M. Fernández, pp. 89-102. Ediciones Universidad de Tarapacá, Arica.

Standen, V., B. Arriaza, C. Santoro y M. Santos 2014. La práctica funeraria en el sitio Maestranza Chinchorro y el poblamiento costero durante el Arcaico Medio en el Extremo Norte de Chile. Latin American Antiquity 25:300-321.

Standen, V. y C. Santoro 1994. Patapatane-1: Temprana Evidencia Funeraria en los Andes de Arica (Norte de Chile) y sus Relaciones. Chungara 26:165-183.

Uribe, M. 2009. El período Formativo de Tarapacá y su cerámica: Avances sobre complejidad social en la costa del Norte Grande de Chile (900 AC-800 DC). Estudios Atacameños 37:5-27.

Uribe, M y P. Ayala 2004. La Alfarería de Quillagua en el contexto Formativo del Norte Grande de Chile (1000 AC-500 DC). Chungara Revista de Antropología Chilena, Vol. Especial Tomo 2, pp. 585-597.

Uribe, M. y E. Vidal 2012. Sobre la secuencia cerámica del período Formativo de Tarapacá (900 a.C.-900 d.C.): estudios en Pircas, Caserones, Guatacondo y Ramaditas, norte de Chile. Chungara Revista de Antropología Chilena 44:209-245.

Uribe, M. y E. Vidal 2015. Pottery and social complexity in Tarapacá: reviewing the development of ceramic technology in the Atacama Desert (northern Chile). En Ceramic Analysis in the Andes: Proceedings of the Session on Andean ceramic characterization, editado por I. Druc, pp.15-35. Deep University Press, Wisconsin.

Villa, P. y E. Mahieu 1991. Breakage patterns of human long bones. Journal of Human Evolution 21 (1):27-48.

Willey, G. y P. Phillips 1958. Method and Theory in American Archaeology. The University of Chicago Press, Chicago and London.

Yacobaccio, H. 2006. Intensificación económica y complejidad social en cazadores-recolectores surdandinos. Boletín de Arqueología PUCP 10:305-320.

Yacobaccio, H. 2012. Intercambio y caravanas de llamas en el sur andino. Comechingonia 16:13-33.

\section{Notas}

1 En Lluta, la investigación se ha concentrado sobre algunos sitios específicamente por Santoro y equipo. En Azapa, en cambio, desde el año 2006, la realización de prospecciones y excavaciones sistemáticas, y dataciones en distintas localidades arqueológicas explican el incremento observado, así como su dispersión espacial (Figura 1).

2 Para disminuir el sesgo investigativo y aumentar la resolución cronológica de ciertas localidades y sitios, desde el año 2010 hemos datados sistemáticamente los estratos inferiores, medios y superiores de variadas ocupaciones arqueológicas de la precordillera (Osorio et al. 2016).

3 La identificación taxonómica se llevó a cabo empleando manuales osteológicos (Pacheco et al. 1979; Sierpe 2015) y una colección de referencia propia de fauna local (FONDECYT 1130808). La cuantificación consistió en la contabilización total de restos (NSP), el número de especímenes óseos identificados por taxón (NISP) (Grayson 1984), y el número mínimo de individuos por taxón (MNI) (Lyman 1994). En este trabajo el MNI se calculó tomando en la unidad anatómica más representada, criterios de edad (fusión de epífisis) y lateralidad (Lyman 1994). El estado de la superficie ósea se observó con una lupa binocular de $40 \mathrm{X}$ y permitió caracterizar el nivel de preservación de los restos empleando los atributos principales de la escala de Behrensmeyer (1978). También se identificaron las evidencias de termo alteración basadas en los cambios de coloración de los restos (Lyman 1994): sin evidencias de combustión: Hueso blanco; Quemado: Manchas de rojas de combustión; Carbonizado: Manchas negras de combustión; Calcinado: Hueso de color gris, blanquecino o azul; Finalmente, las modificaciones antrópicas vinculadas a la extracción intencional de la superficie ósea fueron: Huellas de corte: Marcas horizontales paralelas; Fracturas producidas por el golpe intencional sobre los huesos: Fracturas de forma helicoidal o recta, de borde liso y con evidencias de punto de impacto; Derivados de la percusión ósea: Lascas y láminas óseas (Blumenshine 1995; Blumenshine et al. 1996; DeNigris 2005; Isaac 1967; Johnson 1985; Villa y Mahieu 1991). 